\title{
Biomarkers in nonalcoholic fatty liver disease
}

\author{
Manuela G Neuman MSc PhD ${ }^{1,2}$, Lawrence B Cohen MSc MD ${ }^{3,4}$, Radu M Nanau BSc ${ }^{1,2}$
}

MG Neuman, LB Cohen, RM Nanau. Biomarkers in nonalcoholic fatty liver disease. Can J Gastroenterol Hepatol 2014;28(11):607-618.

BACKGROUND: Nonalcoholic fatty liver disease (NAFLD) is a chronic liver condition characterized by insulin resistance, type 2 diabetes and fat accumulation in the liver that may cause hepatic inflammation and progressive scarring leading to nonalcoholic steatohepatitis (NASH) and irreversible liver damage (cirrhosis). As a result, there has been increased recognition of the need to assess and closely monitor individuals for risk factors of components of NAFLD and NASH, as well as the severity of these conditions using biomarkers.

AIM: To review the biomarkers used to diagnose and define the severity of NAFLD and NASH.

METHODS: A comprehensive PubMed and Google Scholar literature search was performed using the terms "non-alcoholic fatty liver disease", "non-alcoholic steatohepatitis", as well as the name of each biomarker known to be used. Articles indexed between 2004 and 2014 were used. Each author read the publications separately and the results were discussed.

RESULTS: Biomarkers offer a potential prognostic or diagnostic indicator for disease manifestation, progression or both. Serum biomarkers, including total cholesterol, triglycerides, insulin resistance and C-peptide, have been used for many years. Emerging biomarkers, such as apolipoprotein A1, apolipoprotein B, leptin, adiponectin, free fatty acids, ghrelin and tumour necrosis factor-alpha, have been proposed as tools that could provide valuable complementary information to that obtained from traditional biomarkers. Moreover, markers of cell death and mitochondrial dysfunction (cytokeratins) represent powerful predictors of risk. For biomarkers to be clinically useful in accurately diagnosing and treating disorders, age-specific reference intervals that account for differences in sex and ethnic origin are a necessity.

CONCLUSIONS: The present review attempts to provide a comprehensive analysis of the emerging risk biomarkers of NAFLD and NASH, and to use the clinical significance and analytical considerations of each biomarker pointing out sentinel features of disease progression.

Key Words: Adipokines; Apoptosis; Cytokeratin; Nonalcoholic fatty liver disease; Nonalcoholic steatohepatitis; Noninvasive biomarkers; Toll-like receptor; Th1/Th2; Tumour necrosis factor

\section{Les biomarqueurs de la stéatose hépatique non alcoolique}

HISTORIQUE : La stéatose hépatique non alcoolique (SHNA), une maladie hépatique chronique caractérisée par l'insulinorésistance, le diabète de type 2 et l'accumulation de lipides dans le foie, peut être responsable d'une inflammation hépatique et d'une fibrose progressive qui peut entraîner une stéatohépatite non alcoolique (SNA) et une atteinte hépatique irréversible (cirrhose). Par conséquent, on convient de plus en plus de la nécessité d'utiliser des biomarqueurs pour assurer une surveillance étroite des patients. Cette surveillance portera sur les facteurs de risque de divers aspects de la SHNA et de la SNA, ainsi que sur la gravité de ces maladies.

OBJECTIF : Analyser les biomarqueurs utilisés pour diagnostiquer et définir la gravité de la SHNA et de la SNA.

MÉTHODOLOGIE : Les auteurs ont effectué une analyse bibliographique approfondie des articles indexés dans PubMed et Google Scholar entre 2004 et 2014 au moyen des termes non-alcoholic fatty liver disease, nonalcoholic steatohepatitis et du nom de chacun des biomarqueurs qu'ils savaient être utilisés. Chaque auteur a lu les publications séparément et ensemble, ils ont discuté des résultats.

RÉSULTATS : Les biomarqueurs procurent un pronostic potentiel d'indicateurs diagnostiques de manifestations ou d'évolution de la maladie, ou de ces deux problèmes. Les biomarqueurs sériques, y compris le cholestérol total, les triglycérides, l'insulinorésistance et le peptide $\mathrm{C}$, sont utilisés depuis de nombreuses années. Des biomarqueurs émergents, tels que l'apolipoprotéine A1, l'apolipoprotéine B, la leptine, l'adiponectine, les acides gras libres, la ghréline et le facteur de nécrose tumorale alpha, sont des outils susceptibles de fournir de l'information précieuse, qui complétera celle obtenue grâce aux biomarqueurs habituels. De plus, les marqueurs de mort cellulaire et de dysfonction mitochondriale (les cytokératines) sont de puissants prédicteurs de risque. Pour que les biomarqueurs soient utiles sur le plan clinique pour bien diagnostiquer et traiter ces maladies, il faut obtenir des intervalles de référence propres à l'âge qui tiennent compte des différences en fonction du sexe et de l'origine ethnique.

CONCLUSIONS : La présente analyse visait à effectuer un examen approfondi des biomarqueurs émergents du risque de SHNA et de SNA et à utiliser la signification clinique et les considérations analytiques de chaque biomarqueur qui met en lumière les caractéristiques sentinelles d'une évolution pathologique.

$\mathrm{NASH}$, defined as the advanced end of the spectrum of chronic NAFLD, is emerging as an important cause of liver disease. The pathogenesis of NAFLD/NASH and its natural history is captured in liver disease clinics, liver transplantation, diabetes, lipid disorders and obesity. NAFLD/NASH is further studied in pediatric liver and nutrition clinics.

Described by Adler and Schaffner (1) and Ludwig et al (2), NASH is a common manifestation of liver cell injury of various etiologies and of metabolic disorders of fatty acid metabolism. NASH is a chronic liver condition, and can progress to cirrhosis and end-stage liver disease. As the most aggressive form of NAFLD, NASH carries the $\mathrm{NASH}$; however, this intervention often fails to control the disease.

\footnotetext{
${ }^{1}$ In Vitro Drug Safety and Biotechnology; ${ }^{2}$ Department of Pharmacology and Toxicology, Faculty of Medicine, University of Toronto; ${ }^{3}$ Division of Gastroenterology, Sunnybrook Health Sciences Centre; ${ }^{4}$ Department of Internal Medicine, University of Toronto, Toronto, Ontario Correspondence: Dr Manuela G Neuman, Department of Pharmacology and Toxicology, In Vitro Drug Safety and Biotechnology, Banting Institute, 100 College Street, Lab 217, Toronto, Ontario M5G 0A3. Telephone 416-398-4880, fax 416-398-4880, e-mail m_neuman@rogers.com Received for publication June 29, 2014. Accepted October 9, 2014
} 


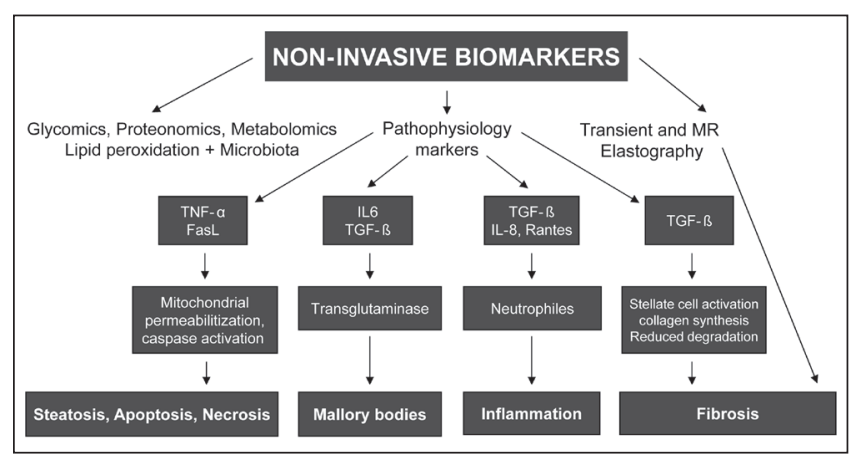

Figure 1) Noninvasive biomarkers. Biomarkers can be measured using several technologies including glycomics, proteomics and/or metabolomics, and imaging techniques such as magnetic resonance (MR) and elastography. Pathophysiology: oxidative stress, lipid peroxidation and activity of microbiota can lead to an increase in mitochondrial permeability and caspase activation. At the tissue level, this leads to steatosis, and death by apoptosis and necrosis. An increase in interleukin (IL) -6 and transforming growth factor (TGF)-beta levels leads to transglutamination, which may induce formation of Mallory-Denk bodies in the cells. An increase in TGF-beta, IL8 and RANTES levels result in the recruitment of neutrophils, leading to cellular inflammation. An increase in TGF-beta levels activates stellate cells and leads to collagen secretion as well as a reduction in extracellular matrix degradation. This phenomenon ultimately results in histological fibrosis. FasL Fas ligand; TNF Tumour necrosis factor

highest risk for adverse outcomes (3). Although risk factors for NASH include obesity, insulin resistance and diabetes, the disease can occur in patients of any ethnic origin, sex or body weight $(4,5)$. Body mass index is a known independent predictor of the degree of hepatic fatty infiltration (6). Although the disease predominantly affects the middleage population, NASH is increasingly recognized in children, commonly in association with obesity (7). The recurrence of NASH in liver-transplant recipients implicates systemic host factors in the development of the disease, rather than liver-related factors (8-11).

Several secondary causes of the typical histological lesions of $\mathrm{NASH}$ are described, including total parenteral nutrition; hypobetalipoproteinemia; jejuno-ileal bypass; certain forms of bariatric surgery; genetic-metabolic diseases such as hereditary tyrosemia type 1, galactosemia, Prader-Willi syndrome, glycogen storage disease, lypodystrophy syndromes, sialidosis, fucosidosis, mannosidosis, citrulinemia, argininemia and porphyria cutanea tarda; and malnutrition and acute starvation (12). Natural toxins, environmental toxic substances, as well as several drugs, including amiodarone, didanosine, hydralazine, methotrexate, tamoxifen, perhexiline, coralgil, corticosteroids and calcium channel blockers, can produce macrovesicular steatosis (12). Gut microbiota, producing lipopolysaccharides, may also sensitize the liver to tumour necrosis factor (TNF)-alpha, leading to hepatotoxicity (12). Toll-like receptor-4 causes nuclear factorkappa B activation and results in TNF-alpha production (12). Histological changes in the liver during NASH are nearly identical to those induced by excessive alcohol intake, as seen in patients with alcoholic steatohepatitis. However, NASH is observed in patients without any evidence of alcohol abuse, which is a flexible definition (13). The separation of NASH from alcoholic liver disease remains based on a history of minimal or no alcohol use. Integral to this definition is the clear identification of a cut-off value for significant alcohol use in light of evidence that even $20 \mathrm{~g} /$ day of alcohol can cause hepatic steatosis (14). In addition, underlying host factors may further confer a greater susceptibility for the development of significant liver disease in the setting of chronic alcohol exposure.

It is believed that NAFLD may be the most prevalent form of liver disease in developed countries (15). Fatty liver not associated with alcohol consumption is now recognized as possibly the most common cause of chronic, asymptomatic liver enzyme elevation in the United States and Europe (16). NASH patients may be asymptomatic or present with mild abdominal pain (17). The liver damage observed in NASH has been well described even though the pathogenesis of the disease remains uncertain. Macrovesicular and/or microvesicular steatosis, ballooning degeneration of hepatocytes, lobular inflammation and, occasionally, cirrhosis characterize the histology of this condition. Steatosis is observed in acinar zone 3, along with zone 3 Mallory bodies and/or acinar zone 3 sinusoidal fibrosis. Morphologically, the mitochondria are swollen, and paracrystalline inclusion bodies can be visualized using electron microscopy. The diagnosis of $\mathrm{NASH}$ requires additional morphological evidence of hepatic injury, ranging from inflammation and hepatocellular ballooning to Mallory's hyaline and fibrosis, the latter ranging from minimal to cirrhosis. The histological features of NAFLD/NASH are identical to those of alcoholic liver injury (18).

Biomarkers can be used as unbiased differential indicators of illness onset, aid in the classification of a diseased or nondiseased state, provide the ability to stage disease progression and/or offer insight into its relative severity. An individual's risk of developing a disorder may also be obtained from biomarker research. As such, a prognostic indicator could be used for risk stratification of the general population. In addition to identifying illnesses, the efficacy of clinical or therapeutic interventions aimed toward these disorders may also be obtained.

Figure 1 illustrates a possible strategy of identifying noninvasive biomarkers based on the methodology used and pathophysiology pathway.

\section{ABNORMAL LIVER FUNCTION TEST RESULTS}

Elevated alanine aminotransferase (ALT) and aspartate aminotransferase (AST) levels reflect nonspecific hepatocellular damage. In NAFLD/NASH, aminotransferase levels may be elevated two to four times over the upper limit of normal (19), with ALT being higher than AST, in contrast to alcoholic steatohepatitis. However, in the absence of advanced disease, routine liver function tests are either normal or typically show only mild elevations in aminotransferase levels, with alkaline phosphatase and gamma-glutamyl transferase (GGT) 1.5 to three times the upper limit of normal.

Several studies involving hepatology clinic patients undergoing liver biopsy and morbidly obese individuals undergoing bariatric surgery have found ALT levels to be higher in the presence of NASH than in those with simple steatosis, although this has not been universally observed (19). However, close to $80 \%$ of patients with fatty liver in cohort studies have shown ALT levels within normal limits (20). Adams et al (21) reported that aminotransferase levels fall over time as hepatic steatosis and inflammation improve. Aminotransferase levels do not correlate with the degree of fibrosis (22).

The diagnostic accuracy of ALT cut-offs for diagnosing NASH was examined in a series of women undergoing bariatric surgery. Reducing the cut-off from $30 \mathrm{IU} / \mathrm{L}$ to $19 \mathrm{IU} / \mathrm{L}$ improved sensitivity for the diagnosis of NASH from $42 \%$ to $72 \%$. However, this was at the expense of specificity, which fell from $80 \%$ to $42 \%$ (23). Patients with NAFLD who have high levels of ALT are, therefore, more likely to have inflammation that may lead to NASH.

\section{MARKERS OF APOPTOSIS}

Cytokeratin (CK)-18 is the major intermediate filament protein of the liver. Caspases cleave CK-18 during hepatocyte apoptosis and create CK-18 fragments that can be detected by immunoassay (24). A recent meta-analysis found a wide range of cut-off values used in M30 assays, based on whether the study authors aimed for 'best sensitivity', 'best specificity' or 'best balance between sensitivity and specificity' to diagnose NASH. Based on the overall analysis, Kwok et al (24) conclude that M30 provides moderate accuracy due to a high variability between cut-offs and respective diagnostic accuracy among studies. Table 1 summarizes recent studies measuring CK-18 and markers of apoptosis (25-36).

Three ELISA-based assays have been recently described to measure CK-18. The M30 assay detects hepatocyte apoptosis through the 
TABLE 1

Biomarkers of apoptosis

\begin{tabular}{|c|c|c|}
\hline Author (reference); study & $\begin{array}{l}\text { Biomarker, } \\
\text { matrix, method }\end{array}$ & Study population, biomarker levels \\
\hline $\begin{array}{l}\text { Fitzpatrick et al (25); } \\
45 \text { pediatric patients with } \\
\text { biopsy-proven NAFLD ( } 8 \\
\text { steatosis, } 17 \text { borderline } \\
\text { NASH and } 20 \text { NASH) vs } \\
13 \text { healthy controls }\end{array}$ & $\begin{array}{l}\text { CK-18 in } \\
\text { plasma using } \\
\text { M30 ELISA }\end{array}$ & $\begin{array}{l}\text { CK-18: median } 288 \text { IU/L (IQR 202-494) in NAFLD vs } \\
\text { 172 IU/L (IQR 146-205) in controls (P<0.001); CK-18: } \\
\text { median } 191 \text { IU/L (IQR 167-197) in simple steatosis, } \\
275 \text { IU/L (IQR 191-508) in borderline NASH and } 347 \\
\text { IU/L (IQR 258-509) in NASH; CK-18: median } 393 \text { IU/L } \\
\text { (IQR 225-533) in severe fibrosis vs } 243 \text { IU/L (IQR } \\
\text { 190-317) in minimal fibrosis ( } P=0.03)\end{array}$ \\
\hline $\begin{array}{l}\text { Papatheodoridis et al (26); } \\
58 \text { patients with biopsy- } \\
\text { proven NAFLD ( } 28 \text { simple } \\
\text { steatosis and } 30 \mathrm{NASH}) \\
\text { vs } 40 \text { healthy volunteers }\end{array}$ & $\begin{array}{l}\text { CK-18 in serum } \\
\text { using M30 } \\
\text { ELISA }\end{array}$ & $\begin{array}{l}\text { CK-18: mean } 148 \mathrm{U} / \mathrm{L} \text { in healthy volunteers vs mean } \\
174 \mathrm{U} / \mathrm{L} \text { in NAFLD }(\mathrm{P}=0.013 \text { vs healthy }) \text { vs mean } 355 \\
\mathrm{U} / \mathrm{L} \text { in } \mathrm{NASH}(\mathrm{P}<0.001 \text { vs both healthy and NAFLD })\end{array}$ \\
\hline $\begin{array}{l}\text { Lebensztejn et al (27); } \\
52 \text { children with biopsy- } \\
\text { proven NAFLD ( } 80.8 \% \\
\text { overweight, } 33 \text { without } \\
\text { fibrosis and } 19 \text { with fibro- } \\
\text { sis) }\end{array}$ & $\begin{array}{l}\text { CK-18 in serum } \\
\text { using M30 } \\
\text { ELISA }\end{array}$ & $\begin{array}{l}\text { CK-18: mean } 215 \mathrm{U} / \mathrm{L}(\mathrm{IQR} 150-342) \text {; CK-18: mean } \\
311.0 \mathrm{U} / \mathrm{L} \text { in fibrosis vs } 177.5 \mathrm{U} / \mathrm{L} \text { without fibrosis } \\
(\mathrm{P}=0.05)\end{array}$ \\
\hline $\begin{array}{l}\text { Tamimi et al (28); } \\
95 \text { patients undergoing } \\
\text { liver biopsy for suspected } \\
\text { NASH (41 NASH and } \\
54 \text { non-NASH) }\end{array}$ & $\begin{array}{l}\text { CK-18 in } \\
\text { plasma using } \\
\text { M30 ELISA; } \\
\text { sFas in } \\
\text { plasma using } \\
\text { ELISA }\end{array}$ & $\begin{array}{l}\text { CK-18: median } 508 \mathrm{U} / \mathrm{L}(\mathrm{IQR} 280-846) \text { in NASH vs } \\
\text { median } 176 \mathrm{U} / \mathrm{L}(\mathrm{IQR} 131-224) \text { in non-NASH } \\
(\mathrm{P}<0.001) \text {; sFas: median } 11.8 \mathrm{ng} / \mathrm{mL}(\mathrm{IQR} 7.8-12.5) \text { in } \\
\text { NASH vs median } 5.9(\text { IQR } 4.8-8.3) \mathrm{ng} / \mathrm{mL} \text { in non- } \\
\text { NASH }(\mathrm{P}<0.001)\end{array}$ \\
\hline $\begin{array}{l}\text { Joka et al (29); } 112 \text { patients } \\
\text { with chronic liver diseases } \\
\text { (22 with NASH/NAFLD } \\
\text { based on histological } \\
\text { examination) vs } 18 \\
\text { healthy individuals }\end{array}$ & $\begin{array}{l}\text { CK-18 in serum } \\
\text { using M30 } \\
\text { ELISA; CK-18 } \\
\text { in serum } \\
\text { using M65 } \\
\text { ELISA; CK-18 } \\
\text { in serum } \\
\text { using M65ED } \\
\text { ELISA }\end{array}$ & $\begin{array}{l}\text { M30: mean }( \pm \mathrm{SD}) 174.1 \pm 12.4 \mathrm{U} / \mathrm{L} \text { in low, } 199.1 \pm 18.3 \\
\mathrm{U} / \mathrm{L} \text { in moderate, and } 346.5 \pm 54.2 \mathrm{U} / \mathrm{L} \text { in high fibrosis } \\
\text { stages }(\mathrm{P}<0.001 \text { for high vs low and moderate); } \mathrm{M} 65 \text { : } \\
503.2 \pm 33.1 \mathrm{U} / \mathrm{L} \text { in low, } 635.2 \pm 65.1 \mathrm{U} / \mathrm{L} \text { in moderate } \\
\text { and } 988.0 \pm 179.4 \mathrm{U} / \mathrm{L} \text { in high }(\mathrm{P}<0.05 \text { for both vs mod- } \\
\text { erate); M65ED: } 429.1 \pm 52.4 \mathrm{U} / \mathrm{L} \text { in low, } 549.6 \pm 73.3 \mathrm{U} / \mathrm{L} \\
\text { in moderate and } 1145.5 \pm 224.7 \mathrm{U} / \mathrm{L} \text { in high }(\mathrm{P}<0.01 \text { for } \\
\text { both vs moderate) }\end{array}$ \\
\hline
\end{tabular}

Associations and diagnostic performance

CK-18: 84\% sensitivity, 88\% specificity, 90\% PPV and

$80 \%$ NPV as a predictor of NASH at a cut-off of

207 IU/L; CK-18: $83 \%$ sensitivity and $40 \%$ specificity

as a predictor of severe fibrosis at a cut-off of $200 \mathrm{IU} / \mathrm{L}$

che

CK-18: sensitivity $70 \%$, specificity $82 \%$, PPV $84 \%$, NPV $73 \%$ for diagnosis of NASH at cut-off of $\geq 225 \mathrm{U} / \mathrm{L}$; CK-18: sensitivity 60\%, specificity $93 \%$, PPV 95\%, NPV $69 \%$ for diagnosis of NASH at cut-off of $\geq 250 \mathrm{U} / \mathrm{L}$; CK-18: sensitivity $53 \%$, specificity $100 \%$, PPV $100 \%$, NPV $67 \%$ for diagnosis of NASHat a cut-off of $\geq 300 \mathrm{U} / \mathrm{L}$ CK-18: $79 \%$ sensitivity, $60 \%$ specificity, 56\% PPV and $82 \%$ NPV for fibrosis in NAFLD at a cut-off of $210 \mathrm{U} / \mathrm{L}$ 52 children with biops using $\mathrm{M} 30$ overweight, 33 without fibrosis and 19 with fibrosis)

CK-18 + sFas: $88 \%$ sensitivity, 89\% specificity, 86\% PPV and $91 \%$ NPV using a best cut-off point derived from a probability of $36.6 \%$ corresponding to a score of -0.5509 based on a risk score model of $6.4894+$ $0.0078 \times \mathrm{CK}-18$ fragments $(\mathrm{U} / \mathrm{L})+0.4668 \times \mathrm{sFas}$ (ng/mL)

M30: $71 \%$ sensitivity and $61 \%$ specificity for fibrosis $\geq F 2$ at a cut-off $157.5 \mathrm{U} / \mathrm{L} ; \mathrm{M} 65: 71 \%$ sensitivity and $67 \%$ specificity for fibrosis $\geq F 2$ at cut-off $479.5 \mathrm{U} / \mathrm{L} ; \mathrm{M} 65 \mathrm{ED}$ : $74 \%$ sensitivity and $68 \%$ specificity for fibrosis stages $\geq F 2$ at a cut-off $353.0 \mathrm{U} / \mathrm{L}$; M30: $64 \%$ sensitivity and $59 \%$ specificity for steatosis $>10 \%$ at a cut-off $144 \mathrm{U} / \mathrm{L}$; M65: $65 \%$ sensitivity and $61 \%$ specificity for steatosis $>10 \%$ at a cut-off 469 U/L; M65ED: $73 \%$ sensitivity and $61 \%$ specificity for steatosis $>10 \%$ at a cut-off $310 \mathrm{U} / \mathrm{L} ; \mathrm{M} 30$ : $75 \%$ sensitivity and $70 \%$ specificity for NASH vs NAFLD at cut-off 149.5 U/L; M65: 100\% sensitivity and $80 \%$ specificity for NASH vs NAFLD at a cut-off $386.0 \mathrm{U} / \mathrm{L}$; M65ED: $100 \%$ sensitivity and $80 \%$ specificity for NASH vs NAFLD at a cut-off $237.0 \mathrm{U} / \mathrm{L}$

\begin{tabular}{|lll}
\hline Shen et al (30); & CK-18 in serum & CK-18: median $103 \mathrm{U} / \mathrm{L}$ in controls vs 263 U/L in non- \\
146 patients with biopsy- & using M30 & NASH and 418 U/L in NASH $(P<0.001)$ \\
proven NAFLD (82 NASH) & ELISA &
\end{tabular}
vs 74 healthy controls

CD-18: $84.2 \%$ sensitivity, 91.9\% specificity, 95.4\% PPV and $74.7 \%$ NPV for NAFLD vs control at cut-off $180 \mathrm{U} / \mathrm{L}$; CD-18: $84.2 \%$ sensitivity, $66.2 \%$ specificity, $71.16 \%$ PPV and $60.2 \%$ NPV for NAFLD vs control at a cut-off of $338 \mathrm{U} / \mathrm{L}$

Shen et al (31); 147 patients with biopsyproven NAFLD vs 74 controls without liver and metabolic diseases
CK-18 in serum M30: median 354 U/L (IQR 221-529) in NAFLD vs 103 using M30 U/L (IQR 80-138) in controls ( $P<0.001)$; M65: median ELISA; CK-18 770 U/L (IQR 539-1010) in NAFLD vs 309 U/L (IQR in serum 249-411) in controls ( $P<0.001)$; M65ED: median 443 using M65 U/L (IQR 202-801) in NAFLD vs $47 \mathrm{U} / \mathrm{L}$ (IQR 30-92) ELISA; CK-18 in controls ( $P<0.001)$; M30: median 277 U/L (IQR 186in serum 472 ) in non-NASH vs 397 U/L (IQR 264-657) in NASH using M65ED $\quad(P=0.001)$; M65: median $637 \mathrm{U} / \mathrm{L}$ (IQR 457-886) in ELISA non-NASH vs $877 \mathrm{U} / \mathrm{L}$ (IQR 671-1469) in NASH $(\mathrm{P}<0.001)$; M65ED: median $271 \mathrm{U} / \mathrm{L}(\mathrm{IQR} 187-579)$ in non-NASH vs 572 U/L (IQR 328-1070) in NASH $(\mathrm{P}<0.001)$
M65: differentiated between grade 1 and grade 2 steatosis $(P=0.008)$; M65ED: differentiated between grade 1 and grade 2 steatosis $(P=0.001)$; M30: did not differentiate between grade 1 and grade 2 steatosis $(P=0.190)$; $M 30: 84.4 \%$ sensitivity, $90.4 \%$ specificity, 94.7\% PPV and $74.2 \%$ NPV for NAFLD vs control at a cut-off of $180 \mathrm{U} / \mathrm{L}$; M65: $76.9 \%$ sensitivity, 95.9\% specificity, 97.4\% PPV and 67.3\% NPV for NAFLD vs control at cut-off $523 \mathrm{U} / \mathrm{L}$; M65ED: $93.2 \%$ sensitivity, 79.5\% specificity, 90.2\% PPV and $85.3 \%$ NPV for NAFLD vs control at cut-off $105 \mathrm{U} / \mathrm{L} ; \mathrm{M} 30: 66.7 \%$ sensitivity, $60.3 \%$ specificity, 59.8\% PPV and $67.2 \%$ NPV for NASH vs non-NASH at cut-off $338 \mathrm{U} / \mathrm{L}$; M65: $62.3 \%$ sensitivity, $70.5 \%$ specificity, $65.1 \%$ PPV and $67.9 \%$ NPV for NASH vs non-NASH at a cut-off $790 \mathrm{U} / \mathrm{L}$; M65ED: $79.7 \%$ sensitivity, $57.7 \%$ specificity, $62.5 \%$ PPV and $76.3 \%$ NPV for NASH vs non-NASH at a cut-off $309 \mathrm{U} / \mathrm{L}$ 
TABLE 1 - CONTINUED

Biomarkers of apoptosis

\begin{tabular}{|c|c|c|c|}
\hline Author (reference); study & $\begin{array}{l}\text { Biomarker, } \\
\text { matrix, method }\end{array}$ & Study population, biomarker levels & Associations and diagnostic performance \\
\hline $\begin{array}{l}\text { Feldstein et al (32); } 201 \\
\text { children with biopsy- } \\
\text { proven NAFLD } \\
\text { (140 NASH) } \\
\end{array}$ & $\begin{array}{l}\text { CK-18 in serum } \\
\text { using M30 } \\
\text { ELISA }\end{array}$ & $\begin{array}{l}\text { CK-18: mean }( \pm \text { SD) } 322.1 \pm 104.8 \mathrm{U} / \mathrm{L} \text { in NASH vs } \\
164.2 \pm 62 \mathrm{U} / \mathrm{L} \text { in non-NASH }(P<0.001)\end{array}$ & $\begin{array}{l}\text { CK-18: } 85.0 \% \text { sensitivity, } 86.9 \% \text { specificity, } 93.7 \% \text { PPV, } \\
71.6 \% \text { NPV for NASH at cut-off of } 233 \text { U/L }\end{array}$ \\
\hline $\begin{array}{l}\text { Kim et al (33); } 108 \text { patients } \\
\text { undergoing liver biopsy for } \\
\text { suspected NASH(1 patient } \\
\text { [1.0\%] NAFLD type } 1 ; 40 \\
\text { [37.0\%] NAFLD type } 2 ; 39 \\
\text { [36.1\%] NAFLD type } 3 \\
\text { and } 28[25.9 \%] \text { NAFLD } \\
\text { type } 4) ; 67(62.0 \%) \text { NASH }\end{array}$ & $\begin{array}{l}\text { CK-18 in serum } \\
\text { using M30 } \\
\text { ELISA }\end{array}$ & $\begin{array}{l}\text { CK-18: mean }( \pm \text { SD) } 279.58 \pm 199.20 \mathrm{U} / \mathrm{L} \text { in NAFLD } \\
\text { subtype } 1 \text { and } 2 \text { vs } 512.20 \pm 636.24 \mathrm{U} / \mathrm{L} \text { in NAFLD } \\
\text { subtype } 3 \text { and } 4(P=0.010)\end{array}$ & $\begin{array}{l}\text { CK-18: } 69.0 \% \text { sensitivity, } 64.9 \% \text { specificity, } 75.5 \% \text { PPV } \\
\text { and } 57.1 \% \text { NPV for NASH at cut-off of } 235.5 \mathrm{U} / \mathrm{L}\end{array}$ \\
\hline $\begin{array}{l}\text { Cusi et al (34); } 424 \text { over- } \\
\text { weight subjects ( } 300 \text { with } \\
\text { NAFLD according to } \\
\text { biopsy or magnetic reso- } \\
\text { nance imaging and spec- } \\
\text { troscopy) }\end{array}$ & $\begin{array}{l}\text { CK-18 in } \\
\text { plasma using } \\
\text { M30 ELISA }\end{array}$ & $\begin{array}{l}\text { CK-18: } 211 \text { U/L (IQR 141-338) in NAFLD vs } 148 \mathrm{U} / \mathrm{L} \\
\text { (IQR 110-195) in non-NAFLD (P<0.0001); CK-18: } \\
\text { 179 U/L (IQR 121-231) in simple steatosis vs 122 U/L } \\
\text { (IQR 98-155) in non-NAFLD (P<0.0001); CK-18: } \\
232 \mathrm{U} / \mathrm{L} \text { (IQR 151-387) in NASH vs 170 U/L } \\
\text { (IQR 135-234) in simple steatosis }(P<0.0001)\end{array}$ & $\begin{array}{l}\text { CK-18: } 63 \% \text { sensitivity, } 83 \% \text { specificity, } 95 \% \text { PPV and } \\
31 \% \text { NPV for NAFLD with a cut-off of } 165 \text { U/L; CK-18: } \\
58 \% \text { sensitivity, } 68 \% \text { specificity, } 75 \% \text { PPV and } 49 \% \\
\text { NPV for NASH with a cut-off of } 212 \text { U/L; CK-18: } 54 \% \\
\text { sensitivity, } 85 \% \text { specificity, } 83 \% \text { PPV and } 56 \% \text { NPV for } \\
\text { fibrosis with a cut-off of } 262 \text { U/L }\end{array}$ \\
\hline $\begin{array}{l}\text { Grigorescu et al (35); } \\
79 \text { patients with biopsy } \\
\text { proven-NAFLD ( } 20 \text { non- } \\
\text { NASH and } 59 \text { NASH) }\end{array}$ & $\begin{array}{l}\text { CK-18 in serum } \\
\text { using M65 } \\
\text { ELISA }\end{array}$ & $\begin{array}{l}\text { CK-18: mean }( \pm \mathrm{SD}) 341.6 \pm 113.2 \mathrm{U} / \mathrm{L} \text { in non-NASH and } \\
682.4 \pm 451.6 \mathrm{U} / \mathrm{L} \text { in } \mathrm{NASH}(\mathrm{P}=0.001)\end{array}$ & $\begin{array}{l}\text { CK-18 M65: } 79.6 \% \text { sensitivity, } 66.7 \% \text { specificity, } 86.8 \% \\
\text { PPV and } 53.8 \% \text { NPV for NASH at cut-off of } \geq 340 \mathrm{U} / \mathrm{L}\end{array}$ \\
\hline $\begin{array}{l}\text { Pirvulescu et al (36); } \\
60 \text { overweight, obese or } \\
\text { morbidly obese NAFLD } \\
\text { patients ( } 47 \text { non-NASH; } \\
13 \text { biopsy-proven NASH) }\end{array}$ & $\begin{array}{l}\text { CK-18 in serum } \\
\text { using M30 } \\
\text { ELISA; CK-18 } \\
\text { in serum } \\
\text { using M65 } \\
\text { ELISA }\end{array}$ & $\begin{array}{l}\text { M30: mean }( \pm \text { SD) } 134.8 \pm 47.3 \mathrm{U} / \mathrm{L} \text { in non-NASH vs } \\
\text { 203.3 } \pm 106.0 \mathrm{U} / \mathrm{L} \text { in } N A S H(P=0.0037) ; \mathrm{M} 65 \text { : } \\
282.3 \pm 169.9 \mathrm{U} / \mathrm{L} \text { in non-NASH vs } 597.7 \pm 427.7 \mathrm{U} / \mathrm{L} \text { in } \\
\text { NASH }(P=0.0004)\end{array}$ & $\begin{array}{l}\text { M30: } 69.2 \% \text { sensitivity, } 65.2 \% \text { specificity, } 36.0 \% \text { PPV } \\
\text { and } 88.2 \% \text { NPV for NASH vs non-NASH at cut-off of } \\
136 \text { U/L; M65: } 69.2 \% \text { sensitivity, } 71.7 \% \text { specificity, } \\
40.9 \% \text { PPV and } 89.2 \% \text { NPV for NASH vs non-NASH } \\
\text { at cut-off of } 389 \mathrm{U} / \mathrm{L}\end{array}$ \\
\hline
\end{tabular}

CK Cytokeratin; IQR Interquartile range; NAFLD Nonalcoholic fatty liver disease; NASH Nonalcoholic steatohepatitis; NPV Negative predictive value; PPV Positive predictive value; sFas Soluble Fas; vs Versus

identification of a caspase-cleaved fragment of CK-18. In contrast, both M65 (M6 capture and M5 detection antibodies) and M65ED (M5 capture and M6 detection antibodies) assays detect total cell death through the identification of both caspase-cleaved and uncleaved CK-18 (29). Measuring serum biomarkers of cell death is considered to be a noninvasive assessment of fibrosis stages in patients with chronic liver disease because apoptosis is involved in liver fibrosis. While CK-18 M30 was unable to differentiate between low and moderate fibrosis stages, CK-18 M65 and CK-18 M65ED showed better predictive value for fibrosis scores $\geq 2$. All three markers functioned similarly in predicting precirrhotic fibrosis scores $\geq 5$. Overall, all three assays could be used effectively to differentiate between NAFLD and NASH; however, only the CK-18 M65 and CK-18 M65ED assays could differentiate between NAFLD and healthy controls (29).

CK-18 M30 was repeatedly found to differentiate between NASH and non-NASH in NAFLD samples. While a clear trend was observed for higher CK-18 levels in patients with more advanced stages of inflammation, steatosis and fibrosis, CK-18 M30 was repeatedly found to be less sensitive, with its usefulness limited by an inability to adequately differentiate between healthy individuals and NAFLD patients. In a large sample of overweight/obese subjects, Cusi et al (34) found significant differences in plasma CK-18 levels using M30 ELISA among all of non-NAFLD, simple steatosis and NASH patients. Differences between controls and non-NASH patients were also found in some smaller samples $(26,30,31)$, while they were absent in other samples $(25,29)$. CK-18 M30 further failed to differentiate between fibrosis stages 1 and 2. In the same study, M65 and M65ED could be used to predict fibrosis stages 1 or 2 (31).

Two models combining CK-18 and hyaluronic acid, and CK-18 and soluble Fas, respectively, showed better predictive value for NASH versus non-NASH in patients with NAFLD $(27,28)$. Soluble Fas ligand was elevated in NAFLD patients with fibrosis compared with NAFLD without fibrosis (37). Elsewhere, double immunohistochemistry staining for CK-8/18 and ubiquitin improved detection of hepatocyte damage in NAFLD. This assay was used to detect ballooned hepatocytes, because ballooned hepatocytes lack CK-8/18 immunostaining on biopsy. Staining was correlated with fibrosis stage, especially advanced fibrosis, and steatohepatitis in 40 adult NAFLD core liver biopsies (38).

The number of hepatic progenitor cells and ductular reaction, assessed by CK-7 immunostaining, was used as an indicator of different fibrosis patterns in 38 pediatric NASH patients (39). Although the incidence of CK-7-positive centrilobular hepatocytes using immunostaining was $64.3 \%$ in 14 needle biopsy liver specimens belonging to NASH patients, CK-7 immunostaining was not associated with the stage of fibrosis or the grade of steatosis. CK-7 immunostaining was more common in patients with elevated serum AST and GGT (40).

Significantly higher caspase 3 and 8 activity was observed in patients with NASH than in simple steatosis in a small sample of 50 NAFLD patients. Mean caspase 3 and 8 activity scores were comparable between patients with normal and patients with elevated ALT levels (41).

\section{ADIPOKINES}

The main adipokines and cytokines involved in the pathogenesis of NAFLD include adiponectin, leptin, resistin, visfatin, TNF-alpha and interleukin (IL)-6 (42). Adiponectin, a $30 \mathrm{kDa}$ protein, is exclusively synthesized by adipose tissue and has roles in glucose and lipid metabolism $(43,44)$. Its secretion is stimulated by insulin and is induced during fat cell differentiation. Adiponectin modifies insulin receptor function and influences hepatocellular free acid metabolism. Circulating levels of adiponectin are negatively associated with insulin resistance, type 2 diabetes and dyslipidemia (45-57). Table 2 details findings of recent studies with respect to adiponectin (34-36,58-65) and leptin $(36,63-66)$ levels in NAFLD patients. 
TABLE 2

Studies investigating adiponectin, leptin, resistin and retinol binding protein 4 in NAFLD patients

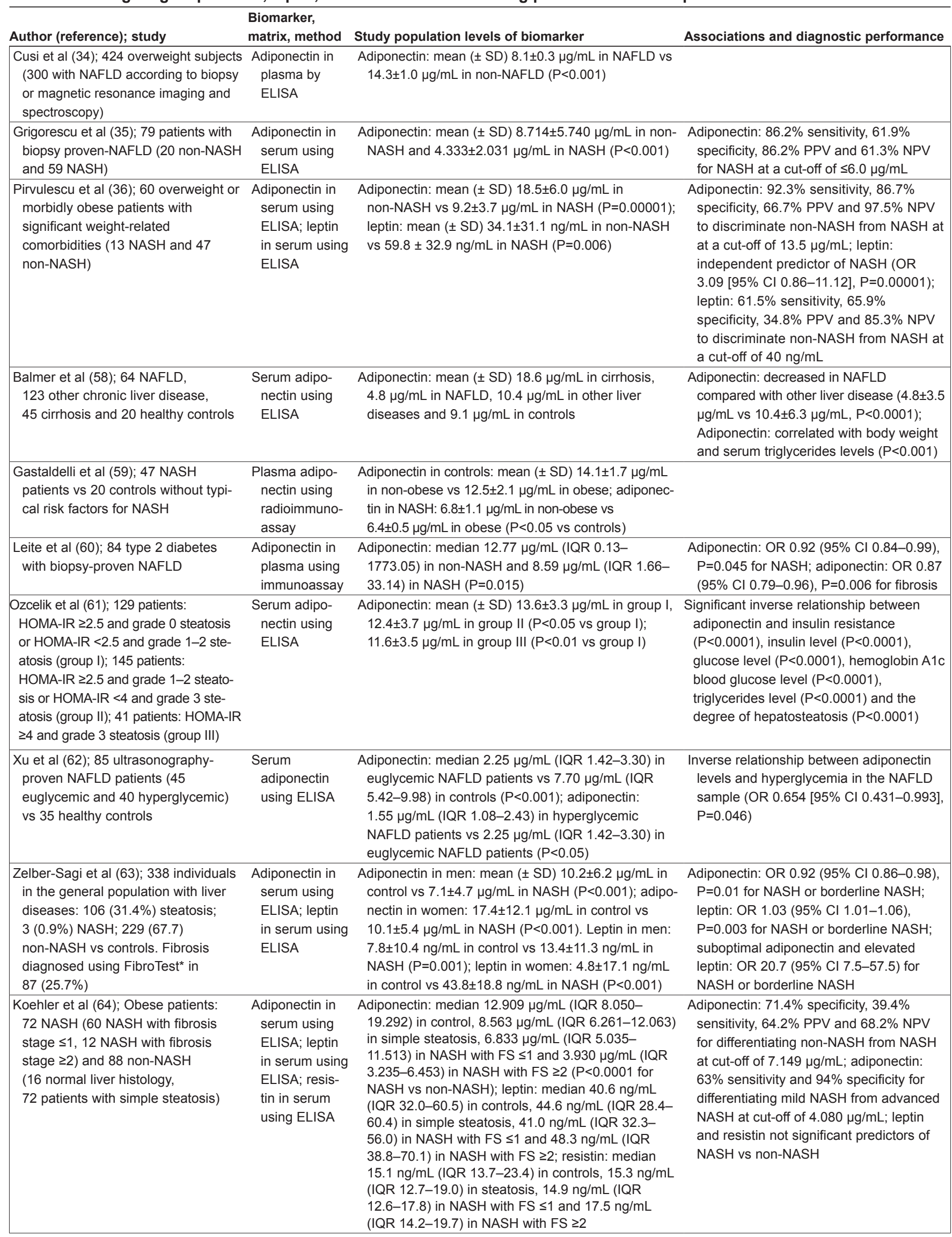


TABLE 2 - CONTINUED

Studies investigating adiponectin, leptin, resistin and retinol binding protein 4 in NAFLD patients

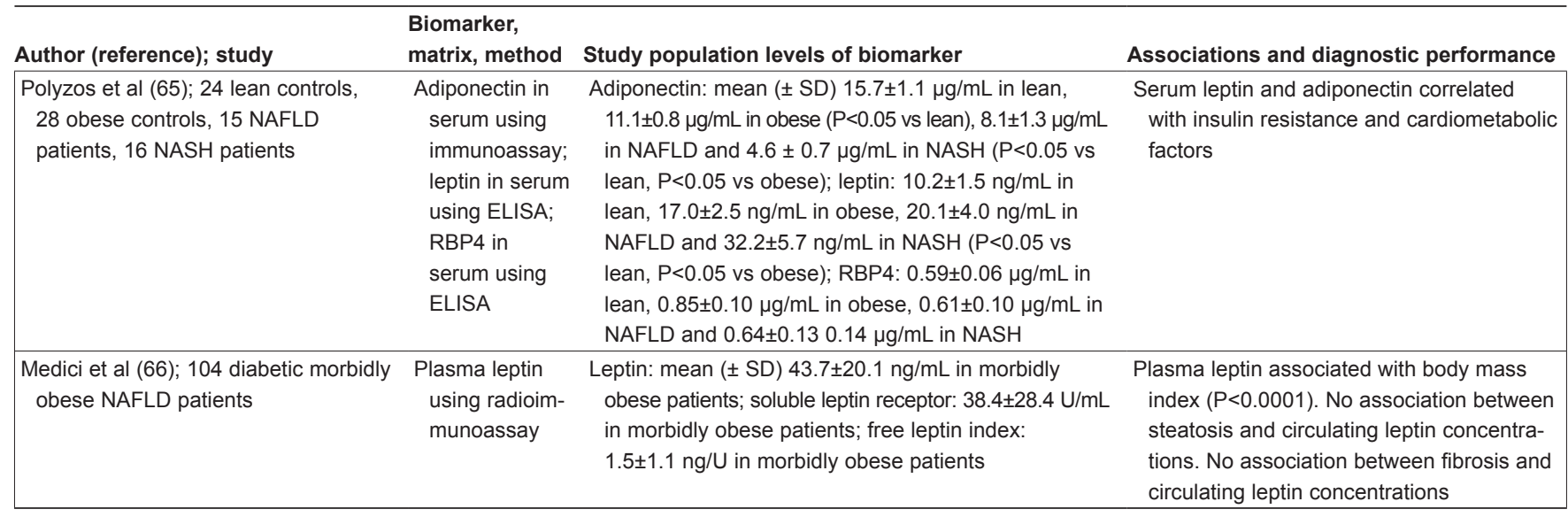

*LabCorp, USA. ELISA Enzyme-linked immunosorbent assay; FS Fibrosis score; HOMA-IR Homeostasis model assessment of insulin resistance; IQR Interquartile range; NAFLD Nonalcoholic fatty liver disease; NASH Nonalcoholic steatohepatitis; NPV Negative predictive value; PPV Positive predictive value; RBP4 Retinol binding protein 4; vs Versus

Mean $( \pm \mathrm{SD})$ adiponectin levels were low $(6.88 \pm 4.50 \mu \mathrm{g} / \mathrm{mL})$ in a small sample of 12 NAFLD patients (67). Serum adiponectin levels were lower in patients with NASH than in those without NASH in small samples of patients with biopsy-proven $\operatorname{NAFLD}(33,35,60,64,68)$. Based on findings from a recent meta-analysis (69), adiponectin is a biomarker of NAFLD progression to NASH because differences in serum adiponectin levels between controls and NAFLD patients are less pronounced. Adiponectin is a negative predictor of NASH in NAFLD patients at a cut-off of $29.16 \mu \mathrm{g} / \mathrm{L}$ (70). Furthermore, adiponectin levels were decreased in NAFLD patients compared with patients with other chronic liver conditions (58). An inverse relationship with fibrosis was also found (60). Adiponectin was not a predictor of either steatosis or fibrosis in a small pediatric NAFLD sample (25).

In a sample of 35 healthy controls and 85 ultrasonography-proven NAFLD patients ( 45 euglycemic and 40 hyperglycemic), serum adiponectin levels were significantly lower in euglycemic NAFLD patients than in controls, and in hyperglycemic compared with euglycemic NAFLD patients. A significant inverse relationship was further found between adiponectin levels and hyperglycemia in the NAFLD sample as a whole (62). Hypoadiponectinemia in NAFLD is part of the metabolic disturbances associated with MS, with a significant inverse relationship found between serum adiponectin levels and hepatic fat content (71). A significant inverse relationship was found between serum adiponectin levels and all of insulin resistance, insulin level, glucose level, hemoglobin A1c blood glucose level and triglycerides level in a large sample of obese male patients. Furthermore, adiponectin levels were higher in individuals with lower hepatosteatosis $(61,65)$.

NASH was associated with an increase in the messenger RNA expression of the adiponectin receptor ApoR2, which was further associated with hepatocellular apoptosis (70). NAFLD progression in morbid obesity is associated with an increase in hepatic adiponectin receptors expression (72).

An inverse correlation was found between adiponectin and bile acids, while a trend was shown between bile acid levels and NASH. This suggests that adiponectin may be protective through its effect on bile acid metabolism (70).

Based on large variations in mean adiponectin levels found in different studies, this adipokine appears unlikely to be useful as a sole diagnostic biomarker in NAFLD/NASH. However, its regular monitoring can aid in assessing NAFLD progressing or regression over time in the same patient. For example, Wong et al (73) found that adiponectin levels increased after a three-year follow-up compared with baseline in NAFLD patients who received dietary counselling and were encouraged to increase physical activity. However, changes in adiponectin levels over this period were not correlated with increased, static or decreased NAFLD activity score (73).

Another prominent adipocytokine associated with NAFLD is leptin. Leptin is a $16 \mathrm{kDa}$ proteohormone that is believed to be involved in the regulation of food intake, energy balance and body weight by increasing energy expenditure $(74,75)$. Leptin is synthesized by differentiated adipocytes but has also been documented in other tissues including skeletal muscle, liver and the placenta (76-79). Leptin concentrations in the blood reflect total body fat (80).

Leptin levels were higher in an obese pediatric population with concomitant NAFLD than in obese control patients without steatosis (68), and in patients with more advanced fibrosis in a small pediatric NAFLD sample (25). Serum leptin was further associated with insulin resistance $(65,81)$. A model combining serum suboptimal adiponectin and elevated leptin was used to predicted NASH or borderline NASH (63).

Increases in leptin levels and decreases in adiponectin levels occurred similarly in patients with simple steatosis or NASH during obesity reversal after bariatric surgery, suggesting that these changes are due to morbid obesity and occur independent of liver disease (82). In a separate study, leptin and adiponectin levels remained independent predictors for NASH in obese patients (36). Similarly, progressive leptin increases and progressive adiponectin decreases occurred with increasing steatosis severity. Leptin increases were further correlated with fibrosis (83). Both leptin and adiponectin were associated with NASH in another study. However, the association between these adipokines and fibrosis assessed by FibroTest (LabCorp, USA) was no longer present (63).

Ghrelin is a 28 amino acid peptide, produced mainly by the stomach, which plays a major role in energy balance $(84,85)$. However, small amounts of ghrelin are synthesized in the hypothalamus, pituitary, bowel, placenta and kidney $(85,86)$. Ghrelin stimulates lactotrophand corticotrophsecretion, and influencesgastroenteropancreatic function and insulin secretion, as well as glucose and lipid metabolism. In addition, ghrelin has cardiovascular and antiproliferative effects $(87,88)$.

Ghrelin has adipogenic properties (85). Ghrelin levels correlate negatively with insulin resistance and hyperinsulinemia, and contribute to the feedback mechanism by which body weight is regulated (89). Low levels of ghrelin are found in diabetic children, which may represent a defense mechanism against hyperglycemia $(90,91)$.

Serum levels of retinol binding protein 4 (RBP4), another adipokine associated with insulin resistance, were also higher in NAFLD patients compared with controls (68). Adiponectin and resistin levels were negatively correlated with leptin and RBP4 levels (68). Based on 
TABLE 3

Noninvasive markers to differentiate disease progression correlated with the gold standard

\begin{tabular}{|c|c|c|}
\hline Correlation & Nonspecific, nonsensitive & Specific, sensitive \\
\hline $\begin{array}{l}\text { Slight correlation with severity of inflammation NAFLD/NASH; } \\
\text { no correlation with fibrosis }\end{array}$ & $\begin{array}{l}\text { Age, body mass index, insulin resistance, } \\
\text { AST/ALT, platelet count, albumin, } \\
\text { haptoglobin, a2-macroglobulin, bilirubin, } \\
\text { y-glutamyl transpeptidase }\end{array}$ & \\
\hline $\begin{array}{l}\text { Correlation with severity of metabolic syndrome NAFLD/NASH; } \\
\text { no correlation with fibrosis or inflammation }\end{array}$ & $\begin{array}{l}\text { Dyslipidemia: triglycerides, cholesterol, } \\
\text { HDL, apolipoprotein A1, apolipoprotein B }\end{array}$ & \\
\hline $\begin{array}{l}\text { Oxidative stress correlated with inflammation steatosis and } \\
\text { ballooning }\end{array}$ & & $\begin{array}{l}\text { Linoleic acid oxidation product: } \\
\text { 13-hydroxy-octadecadienoic acid }\end{array}$ \\
\hline $\begin{array}{l}\text { Adipokine, leptin, higher levels in obese NAFLD patients than in } \\
\text { obese patients without steatosis }\end{array}$ & & Leptin \\
\hline Progression of inflammation & & Ghrelin, ubiquitin sensitive markers for $\mathrm{NASH}$ \\
\hline Sensitive inflammation markers & & $\begin{array}{l}\text { TNF- } \alpha \text {, interleukins (IL-6; IL-8), RANTES and Fas } \\
\text { ligand }\end{array}$ \\
\hline $\begin{array}{l}\text { Mitochondrial dysfunction cytokeratins: provide powerful } \\
\text { predictions of risk in NASH }\end{array}$ & & CK-7/CK-18 \\
\hline
\end{tabular}

ALT Alanine aminotransferase; AST Aspartate aminotransferase; CK Cytokeratin; F1-F4 Fibrosis scores 1 to 4; HDL High-density lipoprotein; RANTES Regulated on activation, normal T cell expressed and secreted; TIMP Tissue inhibitor of metallo-protease; TGF- $\beta$ Transforming growth factor-beta; TNF- $\alpha$ Tumour necrosis factor-alpha

these findings, all of adiponectin, leptin, resistin, ghrelin and retinol RBP4 may be appropriate biomarkers of NAFLD or MS, but are unlikely to serve as diagnostic markers on their own.

\section{CYTOKINES AND INFLAMMATORY MARKERS}

Inflammatory cytokines and chemokines used to diagnose NASH include TNF-alpha and IL-6, the chemokine CC-chemokine ligand-2 (chemo-attractant protein-1), as well as the inflammation marker high-sensitivity C-reactive protein (hs-CRP) (24). Suppression of cytokine signalling-3 downregulates hepatocellular insulin receptors and promotes acquired hepatic insulin resistence (12).

Several recent studies measured inflammatory markers in NAFLD patients $(36,60,92-95)$. Two of these studies compared NAFLD patients with non-NAFLD controls $(92,94)$, while the remaining three compared NASH patients with non-NASH patients in NAFLD cohorts $(36,60,95)$. TNF-alpha was higher in NAFLD patients compared with non-NAFLD controls $(92,94)$. It was also higher in NASH compared with non-NASH in one NAFLD sample (95), while it was comparable between NASH and non-NASH in another (36). IL-6 was higher in NAFLD patients compared with non-NAFLD controls (94), with no differences between NASH and non-NASH $(36,95)$. Another marker of inflammation, hs-CRP, was higher in NAFLD patients compared with non-NAFLD controls $(92,94)$. It was also higher in NASH compared with non-NASH in one NAFLD sample (36), while it was comparable between NASH and non-NASH in other NAFLD samples (93, 95). TNF-alpha, IL-6, IL-8, IL-10, hs-CRP and TNF-beta were similar between NASH and non-NASH, and hence not associated with NASH in a sample of NAFLD patients (60).

\section{CLINICAL PARAMETERS}

Several studies assessed biochemical parameters in NAFLD patients and healthy controls $(30,92,94,96-108)$. In these studies, body mass index or waist circumference, AST, ALT, GGT, triglycerides, glucose, insulin and the homeostasis model assessment of insulin resistance were either significantly higher or showed a trend toward higher levels in NAFLD patients compared with healthy controls. Total cholesterol and low-density lipoprotein levels were similarly higher and high-density lipoprotein levels were lower, with trends observed in smaller samples (30,92,94,96-108). Diabetes mellitus, MS and hypertension were significantly more predominant in NAFLD patients than in controls in these samples $(30,92,98-101,103,107)$. Differences between NAFLD and controls without liver injury were further assessed in obese patients or patients with coronary artery disease (109-112). Similar patterns were observed in obese patients and normal weight patients with respect to metabolic parameters in the presence or absence of NAFLD (109-111). In contrast, metabolic parameters were comparable between NAFLD and normal patients with coronary artery disease (112).

Metabolic profiles were further compared between individuals with simple steatosis and patients with NASH in NAFLD samples. These parameters were often comparable between simple steatosis and NASH, although similar trends as those observed between controls and NAFLD were maintained between simple steatosis and NASH (30,33,35,36,95,113-119). Similarly, the incidence of MS, hypertension and diabetes mellitus was comparable between individuals with simple steatosis and patients with NASH in NAFLD samples (35).

Table 3 illustrates the sensitivity of different biomarkers to differentiate the possible progression of liver damage in NAFLD/NASH.

Markers of MS cannot be used alone to predict NAFLD/NASH, but their periodic monitoring offers an avenue to predict those patients that carry an increased risk of developing NAFLD/NASH, or those at increased risk for disease progression or extrahepatic manifestations.

\section{METABOLOMICS AND PROTEOMICS}

Metabolomics and proteomics are some of the techniques used to identify new markers of NAFLD/NASH. The compounds whose serum levels were observed to differ between patients with NASH and non-NASH controls could be associated with biochemical perturbations associated with liver dysfunction (eg, reduced creatinine) and inflammation (eg, eicosanoid signalling) in an exploratory metabolomics approach using ultra performance liquid chromatography-mass spectrometry (120).

Metabolomics analysis revealed that NAFLD was associated with higher plasma concentrations of homocysteine and total cysteine and 
lower plasma concentrations of total glutathione than controls in nondiabetic subjects with hepatic steatosis or NASH. Markedly higher levels of glycocholate, taurocholate and glyco-cheno-deoxycholate were further observed in subjects with NAFLD. Plasma concentrations of long-chain fatty acids were lower, while those of free carnitine, butyrylcarnitine and methylbutyrylcarnitine were higher in NASH. Several glutamyl dipeptides were also higher and cysteine-glutathione levels were lower in NASH and steatosis (96). Elsewhere, serum metabolomics revealed levels of gamma-Glu-Val, gamma-Glu-Thr, gamma-Glu-Leu, gamma-Glu-His, gamma-Glu-Phe and gamma-GluArg were higher in simple steatosis than in NASH (121). Gammaglutamyl dipeptides, biosynthesized through a reaction with gamma-glutamylcysteine synthetase, indicated production of reduced glutathione (121). Using a metabolomics approach, Li et al (122) further identified serum glucose, glutamate, lactate and taurine levels as biomarkers of NAFLD and constructed a model to predict the different stages of NAFLD progression based on the different levels of these biomarkers in each individual.

A proteomics analysis revealed that the metabolic profile was different depending on an individual's level of obesity. This analysis was useful in distinguishing steatosis from NASH in a sample of patients with biopsy-proven NAFLD (123). Proteomics analysis was used to classify the serum protein fingerprint of NAFLD in 35 NAFLD patients and 35 healthy controls. Hemoglobin subunit $\alpha$ was upregulated in NAFLD compared with controls. High baseline hemoglobin levels predicted an increased risk of developing NAFLD during a three-year follow-up period in a large sample of previously healthy individuals (124).

Using two distinct shotgun proteomic techniques, Miller et al (125) found that several proteins are up/downregulated in NAFLD compared with healthy controls. Of these, afamin, apolipoprotein E, CD5 molecule-like, complement C3, insulin-like growth factorbinding protein 3, vitamin D-binding protein and lymphocyte cytosolic protein 1 were upregulated in serum sample of patients with NAFLD, compared with controls (125). Furthermore, apolipoprotein E, catalase, CD5 molecule-like, lymphocyte cytosolic protein 1 and vitamin D-binding protein were upregulated in serum sample of patients with NASH compared with those with simple steatosis (125).

A recent review by Naik et al (126) discusses the association between NAFLD and genetic variants in different ethnic groups in patatin-like phospholipase domain containing 3, manganese superoxide dismutase $\left(\mathrm{SOD}_{2}\right)$, TNF-alpha, glutathione S-transferases, peroxisome-proliferator-activated receptor-alpha signalling, microsomal triglyceride transfer protein, phosphatidyl-ethanolamine methyltransferase, apolipoprotein C-3, apolipoprotein E, adiponectin signalling, insulin receptor signalling, growth hormone and insulinlike growth factor axis, IL-6, as well as drug-metabolizing enzymes.

\section{MARKERS OF HEPATIC FIBROSIS}

A strong correlation was found between NASH, diabetes mellitus and fibrosis in a large sample of overweight patients (127). Several noninvasive markers of fibrosis have been used in NAFLD patients, including NAFLD fibrosis score, AST/platelet ratio index, FIB-4 score and BARD score. These markers can help predict those patients who would be at highest risk of developing liver-related complications or death (128-130). Advanced fibrosis, inferred from higher scores in these assays, was associated with liver-related adverse events and shorter cumulative survival. Liver-related outcomes were not associated with the degree of steatosis or the presence of NASH, indicating the necessity to adequately assess liver fibrosis, using noninvasive markers, to predict outcomes in NAFLD patients. All four assays successfully differentiated between patients with low risk and patients with higher risk, for both liver-related adverse events and cumulative survival (129). These markers were also used elsewhere to characterize fibrosis (131). These noninvasive fibrosis scoring systems had good negative predictive value but poor positive predictive value, suggesting that they can be used to exclude fibrosis in NAFLD patients and, hence, prevent biopsy in patients without fibrosis (132).
De Lédinghen et al (133) describe a novel physical parameter based on the properties of ultrasonic signals acquired by the FibroScan (Echosens, France). This test, implemented together with FibroScan, can be used with a high degree of sensitivity to simultaneously assess fibrosis and steatosis.

FibroTest is a commercial algorithm based on different biochemical markers used to assess and monitor liver fibrosis progression $(134,135)$. FibroTest further characterized fibrosis in samples of obese patients, identifying those patients with advanced fibrosis and, thus, in need of biopsy (136).

Neuman et al (12) showed that transforming growth factor-beta correlation with fibrosis stages F1 to F3 is strong. However, in patients with cirrhosis, this marker drops significantly because the stellate cells have been reduced (12).

Liver stiffness measurement estimated fibrosis in NAFLD patients. However, no differences were found between stages 1 and 2 of fibrosis (137). Both the pediatric NAFLD fibrosis index and transient elastography were higher in individuals with significant fibrosis in 67 children with biopsy-proven NAFLD (10 with fibrosis stage $\geq 2$ and 57 with fibrosis stage $<2$ ) (138). Combining the two models yielded a cut-off of 8.2 for the pediatric NAFLD fibrosis index, below which clinically significant fibrosis can be ruled out. A pediatric NAFLD fibrosis index score of $\geq 8.2$ led to transient elastography, and a transient elastography score of $<8.6 \mathrm{kPa}$ further revealed early liver fibrosis while a transient elastography score of $\geq 8.6 \mathrm{kPa}$ predicted significant fibrosis with $100 \%$ accuracy and, hence, a need for liver biopsy (138).

\section{OXIDATIVE STRESS}

A strong correlation was found between oxidative stress markers and insulin resistance in obese adolescents with NAFLD (139). Oxidative stress, as indicated by higher plasma reactive carbonyl species levels, may be a direct risk factor for developing NAFLD (140).

Oxidative stress was assessed based on the balance of $\mathrm{SOD}_{2}$, an enzyme with antioxidant activity, and cytochrome p450 2E1 (CYP2E1), an enzyme with pro-oxidant activity, based on data from $100 \mathrm{NASH}$ patients, 31 simple steatosis patients and 90 healthy controls. $\mathrm{SOD}_{2} 47 \mathrm{~T}>\mathrm{C}$ and CYP2E1 $1053 \mathrm{C}>\mathrm{T}$ variants were genotyped using polymerase chain reaction. While the distribution of genetic variants was not different among groups for either enzyme, the presence of the higher activity $\mathrm{SOD}_{2} \mathrm{C}$ allele was higher in NASH patients compared with the other two groups (141).

CYP2E1 plays an important role in fatty acid metabolism, and it leads to the formation of toxic lipid peroxides. A recent study showed that lipid peroxidation was significantly greater in biopsies obtained from pediatric NAFLD patients than in patients with normal liver histology $(\mathrm{P}<0.001)$, without any significant differences in hepatic CYP2E1 expression. Furthermore, lipid peroxidation and CYP2E1 protein content were comparable between patients with simple steatosis and NASH patients (142). Thus, CYP2E1 may be responsible for reactive oxygen species overproduction, which plays an important role in the progression of NAFLD to NASH. While CYP2E1 expression profiles may not differ between simple steatosis and NASH, high CYP2E1 activity may be associated with progression to NASH. Furthermore, increased CYP2E1 expression may be an adaptive mechanism to prevent lipid overload. Recent evidence further shows a correlation between CYP2E1 activity, reactive oxygen species overproduction, mitochondrial assembly of reactive oxygen species and insulin resistance. These effects are detailed in recent reviews (143-145).

In addition, alcohol consumption was found to be a risk factor for $\mathrm{NASH}$, because increased expression and activity of the pathways for alcohol catabolism, including CYP2E1, alcohol dehydrogenase and aldehyde dehydrogenase was found in liver tissues of NASH patients compared with normal controls, suggesting increased scavenging of alcohol from circulation in individuals with NASH (146).

Dietary long-chain fatty acids are an additional source of oxidative stress in NAFLD/NASH. Long-chain fatty acids represent normal 
intermediates in fat metabolism. Depending on the hepatocellular capacity to metabolize free fatty acids, the concentration of long-chain fatty acids and that of their activated form, acyl-coenzyme A, may be lipotoxic. Free fatty acids damage hepatic mitochondria by downregulating their beta oxidation and producing oxidative stress. Furthermore, accumulation of ceramides and diacylglicerol may decrease triglyceride to fatty acid ratio leading to lipotoxicity (147).

\section{CONCLUSION}

Unfortunately, to date, many critical gaps exist in the reference interval database of most of the biomarkers that have been identified for evaluation of hepatic steatosis. In addition, there are critical differences in our current knowledge of the normal levels of these biomarkers in healthy individuals depending on sex, ethnicity, age, nutritional status and comorbidities. The identification of the patients who are at risk for developing steatohepatitis that will advance to cirrhosis and complications of end-stage liver disease remains a challenge. Noninvasive biomarkers are being developed to replace liver biopsy. Hopefully, these biomarkers will provide accurate and reproducible predictive outcome data. A greater understanding of the evolution of the disease must also evaluate the role of lipid metabolism on all liver cells such as hepatocytes, stellate cells and Kupffer cells. The investigation of biomarkers may lead to therapeutic options that could be used to prevent inflammation and fibrosis in the individuals with fatty liver disease. These biomarkers would be a powerful evaluative tool for monitoring of patients with steatohepatitis. The key to a successful prevention program will depend on the early identification, treatment and monitoring of high-risk individuals by measuring a number of disease-specific biomarkers including the ones presented in the present review. Biomarkers are essential to screening and treatment strategies for patients with fatty liver disease, and diagnosing patients with lifethreatening NAFLD and NASH more quickly. This would enable classification and staging of disease using a simple blood test for biomarkers, thus avoiding a liver biopsy. Managing the underlying comorbidities generating NASH syndrome is achievable and should improve the natural history of this challenging disease. In addition, biomarker strategies can platform the biomedical research.

Moreover, we are convinced that the researchers studying MS, in which category NAFLD/NASH belongs, will have to evaluate not only the liver-related mechanisms, biomarkers and injuries, but also other tissues and organs cross-influencing the liver such as the gut, adipose tissue and the central nervous system.

A team in which the biotechnology industry will work with the researcher, hepatologist, cardiologist, endocrinologist and nutrition specialist may be beneficial for the patient.

ACKNOWLEDGEMENTS: In Vitro Drug Safety and Biotechnology and Mahaffy innovative grant - Sunnybrook Health Sciences Centre, Toronto, Ontario supported the work.

DISCLOSURES: The authors have no financial disclosures or conflicts of interest to declare.

\section{REFERENCES}

1. Adler M, Schaffner F. Fatty liver hepatitis and cirrhosis in obese patients. Am J Med 1979;67:811-6.

2. Ludwig J, Viggiano TR, McGill DB, Oh BJ. Nonalcoholic steatohepatitis: Mayo Clinic experiences with a hitherto unnamed disease. Mayo Clin Proc 1980;55:434-8.

3. Bacon BR, Farahvash MJ, Janney CG, Neuschwander-Tetri BA. Nonalcoholic steatohepatitis: An expanded clinical entity. Gastroenterology 1994;107:1103-9.

4. Poonawala A, Nair SP, Thuluvath PJ. Prevalence of obesity and diabetes in patients with cryptogenic cirrhosis: A case-control study. Hepatology 2000;32:689-92.

5. Sanyal AJ, Campbell-Sargent C, Mirshahi F, et al. Nonalcoholic steatohepatitis: Association of insulin resistance and resistance and mitochondrial abnormalities. Gastroeterology 2001;120:1183-92.

6. Popkin BM, Udry JR. Adolescent obesity increases significantly in second and third generation U.S. immigrants: The national longitudinal study of adolescent health. J Nutr 1998;128:701-6.

7. Baldridge AD, Perez-Atayde AR, Graeme-Cook F, Higgins L, Lavine JE. Idopathic steatohepatitis in childhood: A multicenter retrospective study. J Pediatr 1995;127:700-4.

8. Charlton MR, Kondo M, Roberts SK, Steers JL, Krom RA, Wiesner RH. Liver transplantation for crytogenic cirrhosis. Liver Transpl Surg 1997;3:359-64.

9. Czaja AJ. Recurrence of nonalcoholic steatohepatitis after liver transplantation. Liver Transpl Surg 1997;3:185-6.

10. Contos MJ, Cales W, Sterling RK, et al. Development of nonalcoholic fatty liver disease after orthotopic liver transplantation for cryptogenic cirrhosis. Liver Transpl 2001;7:363-73.

11. Keefe EB. Liver transplantation: current status and novel approaches to liver replacement. Gastroenterology 2001;120:749-62.

12. Neuman M, Hilzenrat N, Cohen L, Winkler RE, Nanau R. Multiple factors involved in nonalcoholic hepatitis pathogenesis. Int J Hepatol 2012;2012:429805.

13. Brunt EM, Janney CG, Di Bisceglie AM, Neuschwander-Tetri BA, Bacon BR. Nonalcoholic steatohepatitis: A proposal for grading and staging the histological lesions. Am J Gastroenterol 1999;94:2467-74.

14. Coates RA, Halliday ML, Rankin JG, Feinman SV, Fisher MM. Risk of fatty infiltration or cirrhosis of the liver in relation to ethanol consumption: A case-control study. Clin Invest Med 1986;9:26-32.
15. Angulo P, Lindor KD. Management of nonalcoholic steatohepatitis. In: Krawitt ED, ed. Medical Management of Liver Disease. New York: Marcel Dekker Inc, 1999:367-80.

16. Luyckx FH, Lefebvre PJ, Scheen AJ. Non-alcoholic steatohepatitis: Association with obesity and insulin resistance, and influence of weight loss. Diabetes Metab 2000;26:98-106.

17. Struben VM, Hespenheide EE, Caldwell SH. Nonalcoholic steatohepatitis and cyryptogenic cirrhosis within kindreds. Am J Med 2000;108:9-13.

18. Brunt EM. Nonalcoholic steatohepatitis: Definition and pathology. Semin Liver Dis 2001;21:3-10.

19. Fracanzani AL, Valenti L, Bugianesi E, et al. Risk of severe liver disease in nonalcoholic fatty liver disease with normal aminotransferase levels: A role for insulin resistance and diabetes. Hepatology 2008;48:792-8.

20. Mofrad P, Contos MJ, Haque M, et al. Clinical and histologic spectrum of nonalcoholic fatty liver disease associated with normal ALT values. Hepatology 2003;37:1286-92.

21. Adams LA, Sanderson S, Lindor KD, Angulo P. The histological course of nonalcoholic fatty liver disease: A longitudinal study of 103 patients with sequential liver biopsies. J Hepatol 2005;42:132-8.

22. Mathiesen UL, Frazen LE Fryden A, Foberg U, Bodemar G. The clinical significance of slightly to moderately increases liver transaminase values in asymptomatic patients. Scand J Gastroenterol 1999;34:85-91.

23. Kunde SS, Lazenby AJ, Clements RH, Abrams GA. Spectrum of NAFLD and diagnostic implications of the proposed new normal range for serum ALT in obese women. Hepatology 2005;42:650-6.

24. Kwok R, Tse YK, Wong GL, et al. Systematic review with metaanalysis: Non-invasive assessment of non-alcoholic fatty liver disease - the role of transient elastography and plasma cytokeratin-18 fragments. Aliment Pharmacol Ther 2014;39:254-69.

25. Fitzpatrick E, Mitry RR, Quaglia A, Hussain MJ, DeBruyne R, Dhawan A. Serum levels of CK18 M30 and leptin are useful predictors of steatohepatitis and fibrosis in paediatric NAFLD. J Pediatr Gastroenterol Nutr 2010;51:500-6.

26. Papatheodoridis GV, Hadziyannis E, Tsochatzis E, et al. Serum apoptotic caspase activity in chronic hepatitis $\mathrm{C}$ and nonalcoholic fatty liver disease. J Clin Gastroenterol 2010;44:e87-95.

27. Lebensztejn DM, Wierzbicka A, Socha P, et al. Cytokeratin-18 and hyaluronic acid levels predict liver fibrosis in children with nonalcoholic fatty liver disease. Acta Biochim Pol 2011;58:563-6. 
28. Tamimi TI, Elgouhari HM, Alkhouri N, et al. An apoptosis panel for nonalcoholic steatohepatitis diagnosis. J Hepatol 2011;54:1224-9.

29. Joka D, Wahl K, Moeller S, et al. Prospective biopsy-controlled evaluation of cell death biomarkers for prediction of liver fibrosis and nonalcoholic steatohepatitis. Hepatology 2012;55:455-64.

30. Shen J, Chan HL, Wong GL, et al. Non-invasive diagnosis of nonalcoholic steatohepatitis by combined serum biomarkers. J Hepatol 2012;56:1363-70.

31. Shen J, Chan HL, Wong GL, et al. Assessment of non-alcoholic fatty liver disease using serum total cell death and apoptosis markers. Aliment Pharmacol Ther 2012;36:1057-66.

32. Feldstein AE, Alkhouri N, De Vito R, Alisi A, Lopez R, Nobili V. Serum cytokeratin-18 fragment levels are useful biomarkers for nonalcoholic steatohepatitis in children. Am J Gastroenterol 2013;108:1526-31.

33. Kim YS, Jung ES, Hur W, et al. Noninvasive predictors of nonalcoholic steatohepatitis in Korean patients with histologically proven nonalcoholic fatty liver disease. Clin Mol Hepatol 2013;19:120-30.

34. Cusi K, Chang Z, Harrison S, et al. Limited value of plasma cytokeratin-18 as a biomarker for NASH and fibrosis in patients with non-alcoholic fatty liver disease. J Hepatol 2014;60:167-74.

35. Grigorescu M, Crisan D, Radu C, Grigorescu MD, Sparchez Z, Serban A. A novel pathophysiological-based panel of biomarkers for the diagnosis of nonalcoholic steatohepatitis. J Physiol Pharmacol 2012;63:347-53.

36. Pirvulescu I, Gheorghe L, Csiki I, et al. Noninvasive clinical model for the diagnosis of nonalcoholic steatohepatitis in overweight and morbidly obese patients undergoing bariatric surgery. Chirurgia (Bucur) 2012;107:772-9.

37. Page S, Birerdinc A, Estep M, et al. Knowledge-based identification of soluble biomarkers: hepatic fibrosis in NAFLD as an example. PLoS One 2013;8:e56009.

38. Guy CD, Suzuki A, Burchette JL, et al. Costaining for keratins 8/18 plus ubiquitin improves detection of hepatocyte injury in nonalcoholic fatty liver disease. Hum Pathol 2012;43:790-800.

39. Skoien R, Richardson MM, Jonsson JR, et al. Heterogeneity of fibrosis patterns in non-alcoholic fatty liver disease supports the presence of multiple fibrogenic pathways. Liver Int 2013;33:624-32.

40. Matsukuma S, Takeo H, Kono T, Nagata Y, Sato K. Aberrant cytokeratin 7 expression of centrilobular hepatocytes: A clinicopathological study. Histopathology 2012;61:857-62.

41. Canbakan B, Senturk H, Canbakan M, et al. Is alanine aminotransferase level a surrogate biomarker of hepatic apoptosis innonalcoholic fatty liver disease? Biomark Med 2010;4:205-14.

42. Armutcu F, Akyol S, Ucar F, Erdogan S, Akyol O. Markers in nonalcoholic steatohepatitis. Adv Clin Chem 2013;61:67-125.

43. Silha JV, Krsek M, Skrha JV, Sucharda P, Nyomba BL, Murphy LJ. Plasma resistin, adiponectin and leptin levels in lean and obese subjects: Correlations with insulin resistance. Eur J Endocrinol 2003;149:331-5.

44. Trujillo ME, Scherer PE. Adiponectin - journey from an adipocyte secretory protein to biomarker of the metabolic syndrome. J Intern Med 2005;257:167-75.

45. Scherer PE, Williams S, Fogliano M, Baldini G, Lodish HF. A novel serum protein similar to $\mathrm{Clq}$, produced exclusively in adipocytes. J Biol Chem 1995;270:26746-9.

46. Hu E, Liang P, Spiegelman BM. AdipoQ is a novel adipose-specific gene dysregulated in obesity. J Biol Chem 1996;271:10697-703.

47. Maeda K, Okubo K, Shimomura I, Funahashi T, Matsuzawa Y, Matsubara K. cDNA cloning and expression of a novel adipose specific collagen-like factor, apM1 (AdiPose Most abundant Gene transcript 1). Biochem Biophys Res Commun 1996;221:286-9.

48. Shapiro L, Scherer PE. The crystal structure of a complement-1q family protein suggests an evolutionary link to tumor necrosis factor. Curr Biol 1998;8:335-8.

49. Arita Y, Kihara S, Ouchi N, et al. Paradoxical decrease of an adipose - specific protein, adiponectin, in obesity. Biochem Biophys Res Commun 1999;257:79-83.

50. Ouchi N, Kihara S, Arita Y, et al. Novel modulator for endothelial adhesion molecules: Adipocyte-derived plasma protein adiponectin. Circulation 1999;100:2473-6.

51. Hotta K, Funahashi T, Arita Y, et al. Plasma concentrations of a novel, adipose-specific protein, adiponectin, in Type 2 diabetic patients. Arterioscler Thromb Vasc Biol 2000;20:1595-9.
52. Berg AH, Combs TP, Scherer PE. ACRP30/adiponectin: An adipokine regulating glucose and lipid metabolism. Trends Endocrinol Metab 2002;13:84-9.

53. Lindsay RS, Funahashi T, Hanson RL, et al. Adiponectin and development of Type 2 diabetes in the Pima Indian population. Lancet 2002;360:57-8.

54. Matsubara M, Maruoka S, Katayose S. Decreased plasma adiponectin concentrations in women with dyslipidemia. J Clin Endocrinol Metab 2002;87:2764-9.

55. Yang WS, Lee WJ, Funahashi T, et al. Plasma adiponectin levels in overweight and obese Asians. Obes Res 2002;10:1104-10.

56. Bełtowski J. Adiponectin and resistin - new hormones of white adipose tissue. Med Sci Monit 2003;9:RA55-61.

57. Yamauchi T, Kamon J, Ito Y, et al. Cloning of adiponectin receptors that mediate antidiabetic metabolic effects. Nature 2003;423:762-9.

58. Balmer ML, Joneli J, Schoepfer A, Stickel F, Thormann W, Dufour JF Significance of serum adiponectin levels in patients with chronic liver disease. Clin Sci (Lond) 2010;119:431-6.

59. Gastaldelli A, Harrison S, Belfort-Aguiar R, et al. Pioglitazone in the treatment of NASH: The role of adiponectin. Aliment Pharmacol Ther 2010;32:769-75.

60. Leite NC, Salles GF, Cardoso CR, Villela-Nogueira CA. Serum biomarkers in type 2 diabetic patients with non-alcoholic steatohepatitis and advanced fibrosis. Hepatol Res 2013;43:508-15.

61. Ozcelik F, Yuksel C, Arslan E, Genc S, Omer B, Serdar MA. Relationship between visceral adipose tissue and adiponectin, inflammatorymarkers and thyroid hormones in obese males with hepatosteatosis and insulin resistance. Arch Med Res 2013;44:273-80.

62. Xu YZ, Zhang X, Wang L, et al. An increased circulating angiotensin II concentration is associated with hypoadiponectinemia and postprandial hyperglycemia in men with nonalcoholic fatty liver disease. Intern Med 2013;52:855-61.

63. Zelber-Sagi S, Ratziu V, Zvibel I, et al. The association between adipocytokines and biomarkers for nonalcoholic fatty liver diseaseinduced liver injury: A study in the general population. Eur J Gastroenterol Hepatol 2012;24:262-9.

64. Koehler E, Swain J, Sanderson S, Krishnan A, Watt K, Charlton M Growth hormone, dehydroepiandrosterone and adiponectin levels in non-alcoholic steatohepatitis: An endocrine signature for advanced fibrosis in obese patients. Liver Int 2012;32:279-86.

65. Polyzos SA, Kountouras J, Anastasilakis AD, Geladari EV, Mantzoros CS. Irisin in patients with nonalcoholic fatty liver disease. Metabolism 2014;63:207-17.

66. Medici V, Ali MR, Seo S, et al. Increased soluble leptin receptor levels in morbidly obese patients with insulin resistance and nonalcoholic fatty liver disease. Obesity (Silver Spring) 2010;18:2268-73

67. Baranova A, Tran TP, Afendy A, et al. Molecular signature of adipose tissue in patients with both non-alcoholic fatty liver disease (NAFLD) and polycystic ovarian syndrome (PCOS). J Transl Med 2013;11:133.

68. Boyraz M, Cekmez F, Karaoglu A, Cinaz P, Durak M, Bideci A Serum adiponectin, leptin, resistin and RBP4 levels in obese and metabolic syndrome children with nonalcoholic fatty liver disease. Biomark Med 2013;7:737-45.

69. Polyzos SA, Toulis KA, Goulis DG, Zavos C, Kountouras J. Serum total adiponectin in nonalcoholic fatty liver disease: A systematic review and meta-analysis. Metabolism 2011;60:313-26.

70. Bechmann LP, Kocabayoglu P, Sowa JP, et al. Free fatty acids repress small heterodimer partner (SHP) activation and adiponectin counteracts bile acid-induced liver injury in superobese patients with nonalcoholic steatohepatitis. Hepatology 2013;57:1394-406.

71. Bugianesi E, Pagotto U, Manini R, et al. Plasma adiponectin in nonalcoholic fatty liver is related to hepatic insulin resistance and hepatic fat content, not to liver disease severity. J Clin Endocrinol Metab 2005;90:3498-504.

72. Carazo A, León J, Casado J, et al. Hepatic expression of adiponectin receptors increases with non-alcoholic fatty liver disease progression in morbid obesity in correlation with glutathione peroxidase 1 . Obes Surg 2011;21:492-500.

73. Wong VW, Wong GL, Choi PC, et al. Disease progression of nonalcoholic fatty liver disease: A prospective study with paired liver biopsies at 3 years. Gut 2010;59:969-74.

74. Halaas JL, Gajiwala KS, Maffei M, et al. Weight-reducing effects of the plasma protein encoded by the obese gene. Science 1995;269:543-6. 
75. Friedman JM, Halaas JL. Leptin and the regulation of body weight in mammals. Nature 1998;395:763-70.

76. MacDougald OA, Hwang CS, Fan H, Lane MD. Regulated expression of the obese gene product (leptin) in white adipose tissue and 3T3-L1 adipocytes. Proc Natl Acad Sci U S A 1995;92:9034-7.

77. Rentsch J, Chiesi M. Regulation of ob gene mRNA levels in cultured adipocytes. FEBS Lett 1996;379:55-9.

78. Montague CT, Farooqi IS, Whitehead JP, et al. Congenital leptin deficiency is associated with severe early-onset obesity in humans. Nature 1997;387:903-8.

79. Baratta M. Leptin - from a signal of adiposity to a hormonal mediator in peripheral tissues. Med Sci Monit 2002;8:RA282-92.

80. Considine RV, Sinha MK, Heiman ML, et al. Serum immunoreactive-leptin concentrations in normal weight and obese humans. N Engl J Med 1996;334:292-5.

81. Caro JF, Sinha MK, Kolaczynski JW, Zhang PL, Considine RV. Leptin: the tale of an obesity gene. Diabetes 1996;45:1455-62.

82. Felipo V, Urios A, García-Torres ML, et al. Alterations in adipocytokines and cGMP homeostasis in morbid obesity patients reverse after bariatric surgery. Obesity (Silver Spring) 2013;21:229-37.

83. Machado MV, Coutinho J, Carepa F, Costa A, Proença H, Cortez-Pinto H. How adiponectin, leptin, and ghrelin orchestrate together and correlate with the severity of nonalcoholic fatty liver disease. Eur J Gastroenterol Hepatol 2012;24:1166-72.

84. Broglio F, Arvat E, Benso A, et al. Ghrelin: Endocrine and nonendocrine actions. J Pediatr Endocrinol Metab 2002;15(Suppl 5):1219-27.

85. Muccioli G, Tschop M, Papotti M, Deghenghi R, Heiman M, Ghigo E. Neuroendocrine and peripheral activities of ghrelin: Implications in metabolism and obesity. Eur J Pharmacol 2002;440:235-54.

86. Yoshihara F, Kojima M, Hosoda H, Nakazato M, Kangawa K. Ghrelin: A novel peptide for growth hormone release and feeding regulation. Curr Opin Clin Nutr Metab Care 2002;5:391-5.

87. Kojima M, Hosoda H, Matsuo H, Kangawa K. Ghrelin: Discovery of the natural endogenous ligand for the growth hormone secretagogue receptor. Trends Endocrinol Metab 2001;12:118-22.

88. Casanueva FF, Dieguez C. Ghrelin: The link connecting growth with metabolism and energy homeostasis. Rev Endocr Metab Disord 2002;3:325-38.

89. McLaughlin T, Abbasi F, Lamendola C, Frayo RS, Cummings DE. Plasma ghrelin concentrations are decreased in insulin-resistant obese adults relative to equally obese insulin-sensitive controls. J Clin Endocrinol Metab 2004;89:1630-5.

90. Nagaya N, Kojima M, Uematsu M, et al. Hemodynamic and hormonal effects of human ghrelin in healthy volunteers. Am J Physiol: Regul Integr Comp Physiol 2001;280:R1483-7.

91. Soriano-Guillen L, Barrios V, Lechuga-Sancho A, Chowen JA, Argente J. Response of circulating ghrelin levels to insulin therapy in children with newly diagnosed type 1 diabetes mellitus. Pediatr Res 2004;55:830-5.

92. Kim YC, Cho YK, Lee WY, et al. Serum adipocyte-specific fatty acidbinding protein is associated with nonalcoholic fatty liver disease in apparently healthy subjects. J Nutr Biochem 2011;22:289-92.

93. Tomita K, Teratani T, Yokoyama H, et al. Serum immunoglobulin a concentration is an independent predictor of liver fibrosis in nonalcoholic steatohepatitis before the cirrhotic stage. Dig Dis Sci 2011;56:3648-54.

94. Genc H, Dogru T, Kara M, et al. Association of plasma visfatin with hepatic and systemic inflammation in nonalcoholic fatty liver disease. Ann Hepatol 2013;12:548-55.

95. Nobili V, Siotto M, Bedogni G, et al. Levels of serum ceruloplasmin associate with pediatric nonalcoholic fatty liver disease. J Pediatr Gastroenterol Nutr 2013;56:370-5.

96. Kalhan SC, Guo L, Edmison J, et al. Plasma metabolomic profile in nonalcoholic fatty liver disease. Metabolism 2011;60:404-13.

97. Koga M, Saito H, Mukai M, Saibara T, Kasayama S. Serum dehydroepiandrosterone sulphate levels in patients with nonalcoholic fatty liver disease. Intern Med 2011;50:1657-61.

98. Yilmaz Y, Kurt R, Gurdal A, et al. Circulating vaspin levels and epicardial adipose tissue thickness are associated with impaired coronary flow reserve in patients with nonalcoholic fatty liver disease. Atherosclerosis 2011;217:125-9.

99. Yilmaz Y, Yonal O, Eren F, et al. Serum zinc- $\alpha 2$-glycoprotein concentrations in patients with non-alcoholic fatty liver disease. Clin Chem Lab Med 2011;49:93-7.
100. Yilmaz Y, Eren F, Yonal O, et al. Serum progranulin as an independent marker of liver fibrosis in patients with biopsy-proven nonalcoholic fatty liver disease. Dis Markers 2011;31:205-10.

101. Colak Y, Senates E, Ozturk O, et al. Serum concentrations of human insulin-like growth factor-1 and levels of insulin-like growth factor-binding protein-5 in patients with nonalcoholic fatty liver disease: Association with liver histology. Eur J Gastroenterol Hepatol 2012;24:255-61.

102. Dogru T, Genc H, Tapan S, et al. Elevated asymmetric dimethylarginine in plasma: an early marker for endothelial dysfunction in non-alcoholic fatty liver disease? Diabetes Res Clin Pract 2012;96:47-52.

103. Eren F, Kurt R, Ermis F, Atug O, Imeryuz N, Yilmaz Y. Preliminary evidence of a reduced serum level of fibroblast growth factor 19 in patients with biopsy-proven nonalcoholic fatty liver disease. Clin Biochem 2012;45:655-8.

104. Miyazaki M, Kato M, Tanaka K, et al. Increased hepatic expression of dipeptidyl peptidase-4 in non-alcoholic fatty liver disease and its association with insulin resistance and glucose metabolism. Mol Med Rep 2012;5:729-33.

105. Polyzos SA, Kountouras J, Patsiaoura K, et al. Serum homocysteine levels in patients with nonalcoholic fatty liver disease. Ann Hepatol 2012;11:68-76.

106. Kucukazman M, Ata N, Yavuz B, et al. Evaluation of early atherosclerosis markers in patients with nonalcoholic fatty liver disease. Eur J Gastroenterol Hepatol 2013;25:147-51.

107. Xu C, Yu C, Ma H, Xu L, Miao M, Li Y. Prevalence and risk factors for the development of nonalcoholic fatty liver disease in a nonobese Chinese population: The Zhejiang Zhenhai Study. Am J Gastroenterol 2013;108:1299-304.

108. Cuthbertson DJ, Irwin A, Pugh CJ, et al. Ectopic lipid storage in Non-Alcoholic Fatty Liver Disease is not mediated by impaired mitochondrial oxidative capacity in skeletal muscle. Clin Sci (Lond) 2014 (In press).

109. Espino A, Villagrán A, Vollrath V, et al. Plasminogen activator inhibitor type 1 serum levels and $4 \mathrm{G} / 5 \mathrm{G}$ gene polymorphism in morbidly obese Hispanic patients with non-alcoholic fatty liver disease. Ann Hepatol 2011;10:493-501.

110. Simental-Mendía LE, Rodríguez-Hernández H, Rodríguez-Morán M, Guerrero-Romero F. The alanine aminotransferase to triglycerides ratio as a marker to identify nonalcoholic fatty liver disease. Eur J Gastroenterol Hepatol 2012;24:1173-7.

111. Navarro-Jarabo JM, Ubiña-Aznar E, Tapia-Ceballos L, et al. Hepatic steatosis and severity-related factors in obese children. J Gastroenterol Hepatol 2013;28:1532-8.

112. Ballestri S, Meschiari E, Baldelli E, et al. Relationship of serum fetuin-A levels with coronary atherosclerotic burden and NAFLD in patients undergoing elective coronary angiography. Metab Syndr Relat Disord 2013;11:289-95.

113. Manousou P, Kalambokis G, Grillo F, et al. Serum ferritin is a discriminant marker for both fibrosis and inflammation in histologically proven non-alcoholic fatty liver disease patients. Liver Int 2011;31:730-9.

114. Younossi ZM, Page S, Rafiq N, et al. A biomarker panel for non-alcoholic steatohepatitis (NASH) and NASH-related fibrosis. Obes Surg 2011;21:431-9.

115. De Vito R, Alisi A, Masotti A, et al. Markers of activated inflammatory cells correlate with severity of liver damage in children with nonalcoholic fatty liver disease. Int J Mol Med 2012;30:49-56.

116. Mallea-Gil MS, Ballarino MC, Spiraquis A, et al. IGF-1 levels in different stages of liver steatosis and its association with metabolic syndrome. Acta Gastroenterol Latinoam 2012;42:20-6.

117. Pihlajamäki J, Kuulasmaa T, Kaminska D, et al. Serum interleukin 1 receptor antagonist as an independent marker of nonalcoholic steatohepatitis in humans. J Hepatol 2012;56:663-70.

118. Razavizade M, Jamali R, Arj A, Talari H. Serum parameters predict the severity of ultrasonographic findings in non-alcoholic fatty liver disease. Hepatobiliary Pancreat Dis Int 2012;11:513-20.

119. Ogawa Y, Imajo K, Yoneda M, et al. Soluble CD14 levels reflect liver inflammation in patients with nonalcoholic steatohepatitis. PLoS One 2013;8:e65211.

120. Barr J, Vázquez-Chantada M, Alonso C, et al. Liquid chromatography-mass spectrometry-based parallel metabolic profiling of human and mouse model serum reveals putative biomarkers associated with the progression of nonalcoholic fatty liver disease. J Proteome Res 2010;9:4501-12. 
121. Soga T, Sugimoto M, Honma M, et al. Serum metabolomics reveals $\gamma$-glutamyl dipeptides as biomarkers for discrimination among different forms of liver disease. J Hepatol 2011;55:896-905.

122. Li H, Wang L, Yan X, et al. A proton nuclear magnetic resonance metabonomics approach for biomarker discovery in nonalcoholic fatty liver disease. J Proteome Res 2011;10:2797-806.

123. Barr J, Caballería J, Martínez-Arranz I, et al. Obesity-dependent metabolic signatures associated with nonalcoholic fatty liver disease progression. J Proteome Res 2012;11:2521-32.

124. Yu C, Xu C, Xu L, Yu J, Miao M, Li Y. Serum proteomic analysis revealed diagnostic value of hemoglobin for nonalcoholic fatty liver disease. J Hepatol 2012;56:241-7.

125. Miller M, Walsh S, Atirh A, Huang JT, Ferguson MA, Dillon JF. The serum proteome of non-alcoholic fatty liver disease - a multimodal approach to discovery of biomarkers of non-alcoholic steatohepatitis. J Gastroenterol Hepatol 2014 (In press).

126. Naik A, Košir R, Rozman D. Genomic aspects of NAFLD pathogenesis. Genomics 2013;102:84-95.

127. Loomba R, Abraham M, Unalp A, Wilson L, Lavine J, Doo E, Bass NM. Association between diabetes, family history of diabetes, and risk of nonalcoholicsteatohepatitis and fibrosis. Hepatology 2012;56:943-51.

128. Shah AG, Lydecker A, Murray K, Tetri BN, Contos MJ, Sanyal AJ. Comparison of noninvasive markers of fibrosis in patients with nonalcoholic fatty liver disease. Clin Gastroenterol Hepatol 2009; 7:1104-12.

129. Angulo P, Bugianesi E, Bjornsson ES, et al. Simple noninvasive systems predict long-term outcomes of patients with nonalcoholic fatty liver disease. Gastroenterology 2013;145:782-9.e4.

130. Yoneda M, Imajo K, Eguchi Y, et al. Noninvasive scoring systems in patients with nonalcoholic fatty liver disease with normal alanine aminotransferase levels. J Gastroenterol 2013;48:1051-60.

131. Pérez-Gutiérrez OZ, Hernández-Rocha C, Candia-Balboa RA, et al. Validation study of systems for noninvasive diagnosis of fibrosis in nonalcoholic fatty liver disease in Latin population. Ann Hepatol 2013;12:416-24.

132. McPherson S, Stewart SF, Henderson E, Burt AD, Day CP. Simple non-invasive fibrosis scoring systems can reliably exclude advanced fibrosis in patients with non-alcoholic fatty liver disease. Gut 2010;59:1265-9.

133. de Lédinghen V, Vergniol J, Foucher J, Merrouche W, le Bail B. Non-invasive diagnosis of liver steatosis using controlled attenuation parameter (CAP) and transient elastography. Liver Int 2012;32:911-8.

134. Poynard T, Lassailly G, Diaz E, et al. Performance of biomarkers FibroTest, ActiTest, SteatoTest, and NashTest in patients with severe obesity: meta analysis of individual patient data. PLoS One 2012;7:e30325.

135. Poynard T, Munteanu M, Deckmyn O, et al. Validation of liver fibrosis biomarker (FibroTest) for assessing liver fibrosis progression: Proof of concept and first application in a large population. J Hepatol 2012;57:541-8.

136. Lassailly G, Caiazzo R, Hollebecque A, et al. Validation of noninvasive biomarkers (FibroTest, SteatoTest, and NashTest) for prediction of liver injury in patients with morbid obesity. Eur J Gastroenterol Hepatol 2011;23:499-506.

137. Cao CY, Li YY, Zhou YJ, Nie YQ, Wan YJ. The C-681G polymorphism of the PPAR $-\gamma$ gene is associated with susceptibility to non-alcoholic fatty liver disease. Tohoku J Exp Med 2012;227:253-62.

138. Alkhouri N, Sedki E, Alisi A, Lopez R, Pinzani M, Feldstein AE, Nobili V. Combined paediatric NAFLD fibrosis index and transient elastography to predict clinically significant fibrosis in children with fatty liver disease. Liver Int 2013;33:79-85.

139. Pirgon Ö, Bilgin H, Çekmez F, Kurku H, Dündar BN. Association between insulin resistance and oxidative stress parameters in obese adolescents with non-alcoholic fatty liver disease. J Clin Res Pediatr Endocrinol 2013;5:33-9.

140. Liu S, Shi W, Li G, et al. Plasma reactive carbonyl species levels and risk of non-alcoholic fatty liver disease. J Gastroenterol Hepatol 2011;26:1010-5.

141. Huang YS, Chang CH, Lin TL, Perng CL. Genetic variations of superoxide dismutase 2 and cytochrome P450 2E1 in non-alcoholic steatohepatitis. Liver Int 2014 (In press).

142. Bell LN, Molleston JP, Morton MJ, et al. Hepatic lipid peroxidation and cytochrome P-450 2E1 in pediatric nonalcoholic fatty liver disease and its subtypes. J Clin Gastroenterol. 2011;45:800-7.

143. Aubert J, Begriche K, Knockaert L, Robin MA, Fromenty B. Increased expression of cytochrome P450 2E1 in nonalcoholic fatty liver disease: Mechanisms and pathophysiological role. Clin Res Hepatol Gastroenterol. 2011;35:630-7.

144. Daly AK. Relevance of CYP2E1 to non-alcoholic fatty liver disease. Subcell Biochem. 2013;67:165-75.

145. Leung TM, Nieto N. CYP2E1 and oxidant stress in alcoholic and non-alcoholic fatty liver disease. J Hepatol 2013;58:395-8.

146. Baker SS, Baker RD, Liu W, Nowak NJ, Zhu L. Role of alcohol metabolism in non-alcoholic steatohepatitis. PLoS One 2010;5:e9570.

147. Chavez A, Hollanda WL, Bar J, Sandhoff K, Summers SA. Acid ceramidase overexpression prevents the inhibitory effects of saturated fatty acid on insulin signaling. J Biol Chem 2005;280:20148-53. 


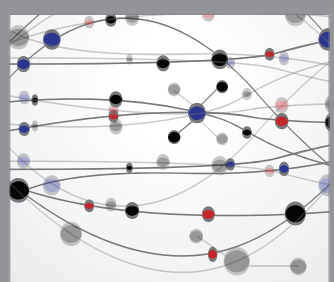

The Scientific World Journal
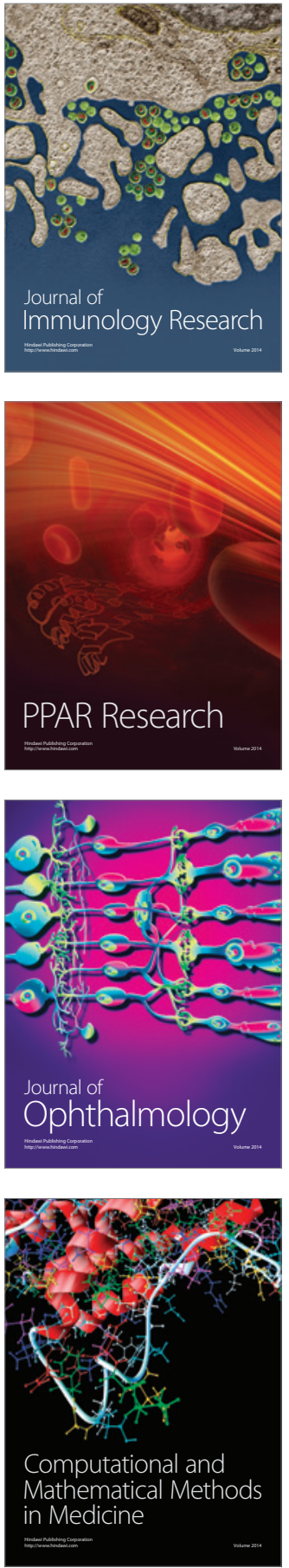

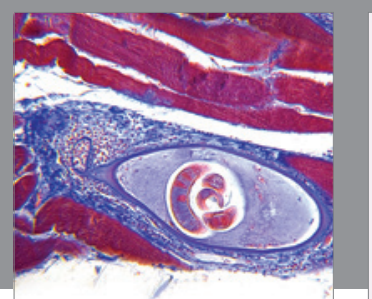

Gastroenterology Research and Practice

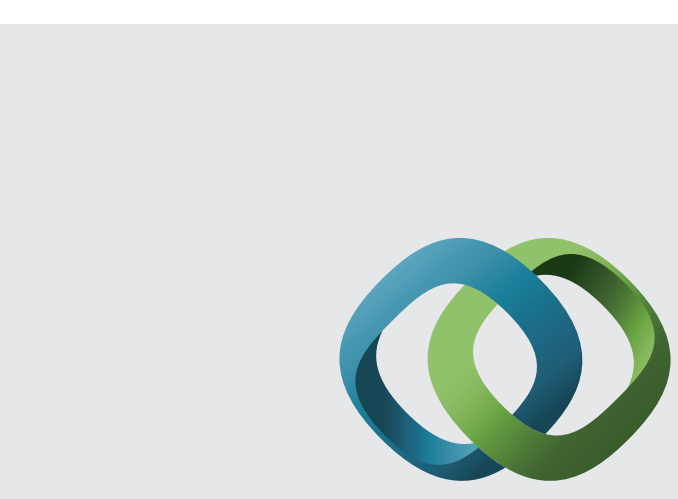

\section{Hindawi}

Submit your manuscripts at

http://www.hindawi.com
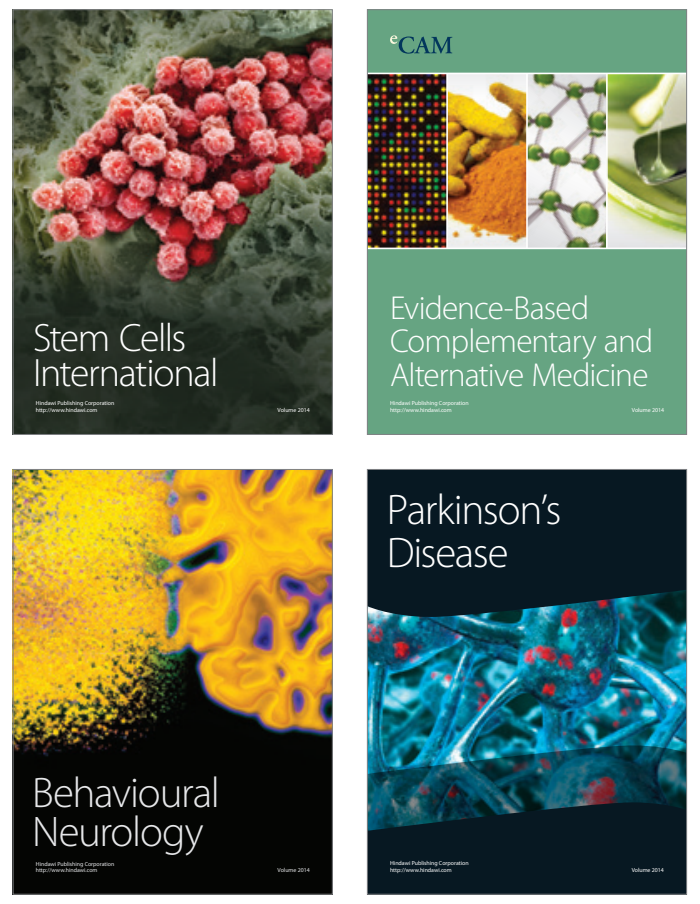
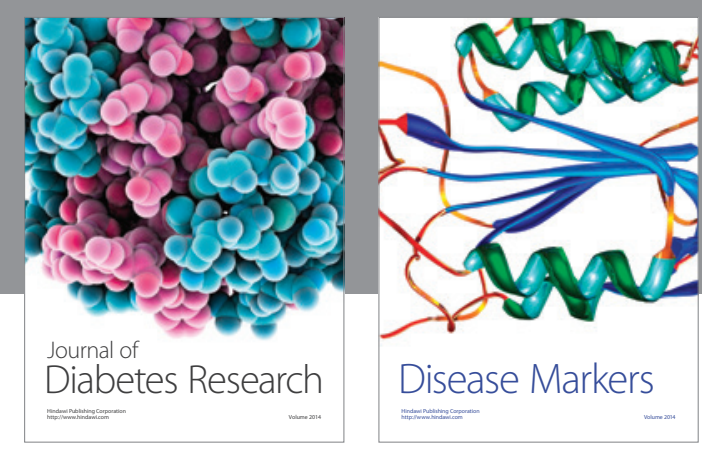

Disease Markers
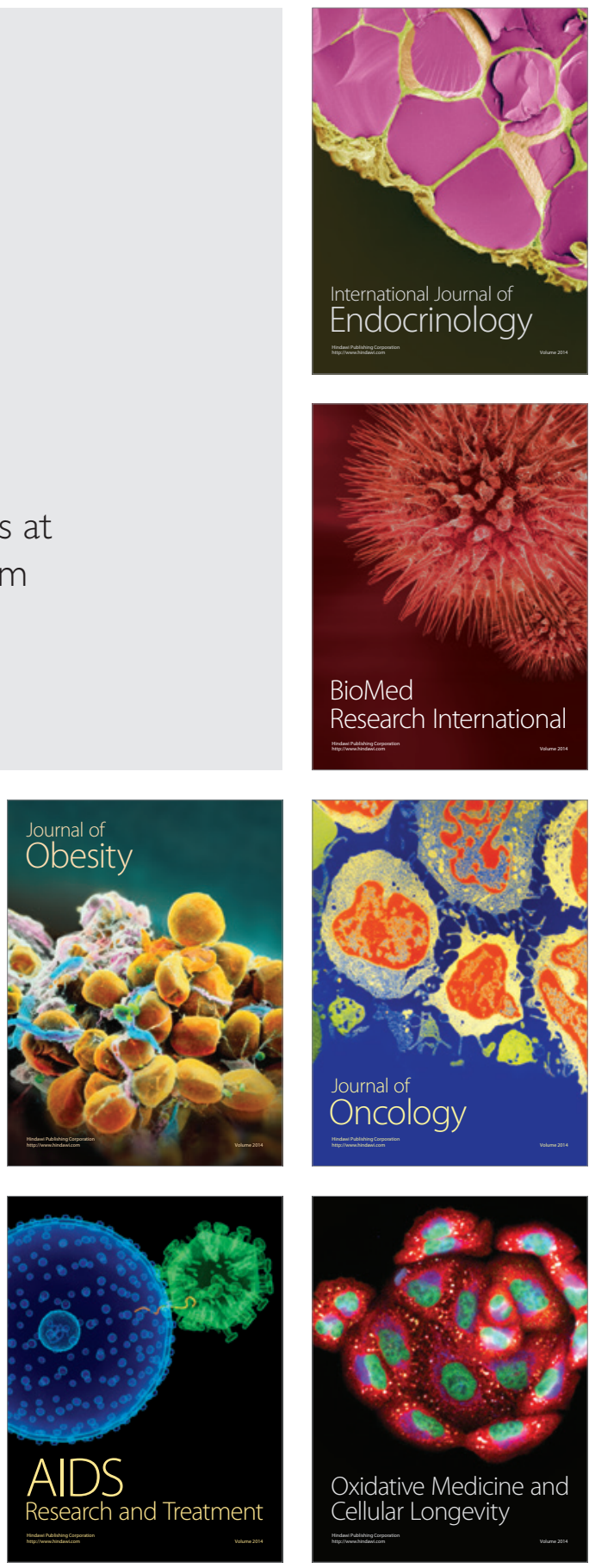